\title{
Propuesta de Sistematización DE LA CERÁMiCA BAJOMEdieVAl De TeRUEL
}

\section{Proposal for a Typology of the Late Middle Ages Ceramics from Teruel}

DIANA PÉREZ-PIÁ (D)

\section{RESUMEN:}

Entendiendo que el valor de una producción cerámica no sólo reside en los objetos que la constituyen sino en posibilitar un mayor conocimiento de la sociedad que le dio uso, resulta significativa la inexistencia de una tipología sobre aquella producida en los alfares de Teruel durante época bajomedieval. Con dicha carencia como principal motivación, se presenta una propuesta sistemática formal de la misma basada en la observación, estudio y clasificación de materiales bajo criterios homogéneos. Se pretende así una aproximación a su evolución y desarrollo, incluyendo posibles influencias recibidas y paralelos en producciones coetáneas.

Palabras clave: cerámica, sistematización, Teruel, Baja Edad Media.

\section{Abstract:}

Considering that the value of a ceramic production not only exists in the objects themselves but also in that they give an insight into their contemporary society, the absence of a corresponding typology for the Teruel region during the late Medieval period stands out. With this lack of knowledge as the main motivation, a formal systematic proposal (based on the observation, study and classification of materials under homogeneous criteria) for this production is therefore presented. Through this, an approximation of its evolution and development is proposed, including possible influences externally received and existing parallels with coexistent productions.

Key words: pottery, typology, Teruel, Late Middle Ages. 


\section{INTRODUCCIÓN}

La denominación cerámica bajomedieval de Teruel reúne todo el conjunto de piezas producidas en los alfares de dicha ciudad entre los ss. XIII y XV, periodo en el cual la villa se caracterizó social y etnográficamente por la coexistencia de las culturas cristiana, judía y musulmana. Esta particular circunstancia dio lugar a una manufactura que combinó formas, técnicas y motivos decorativos propios de tradiciones anteriores con otros más novedosos.

Pese a la pluralidad y riqueza de formas y decoraciones que presenta, todavía hoy existe una sorprendente falta de estudios sistemáticos o tipológicos sobre la cerámica turolense, especialmente si se compara con alfares peninsulares coetáneos. Por ello, el principal objetivo de este artículo es ofrecer una primera e inicial sistematización como posible punto de partida para posteriores estudios, planteada de modo que pueda ser fácilmente corregida y ampliada

\section{PRESENTACIÓN DEL CONJUNTO}

Los fragmentos y piezas cerámicas estudiadas pertenecen en su gran mayoría a los fondos del Museo Provincial de Teruel, procedentes de las diversas intervenciones arqueológicas realizadas en solares de la ciudad. Asimismo, se han considerado y revisado piezas pertenecientes a las colecciones de las siguientes instituciones: Museu del Disseny de Barcelona, Museo de Albarracín, Museo Nacional de Artes Decorativas, Instituto Valencia de Don Juan, Museo Nacional de Cerámica y Artes Suntuarias "González Martî", Museo Arqueológico Nacional, The Hispanic Society of America y The Metropolitan Museum of Art.

El marco cronológico de todas ellas coincide con la segundad mitad del periodo bajomedieval, comprendiendo desde el último tercio del s. XIII, fecha estimada de inicio de la producción cerámica bajo dominio cristiano en Teruel (Álvaro 2002: 34), hasta el final del XV, cuando tiene lugar la transición de la Edad Media a la Época Moderna.

\section{METODOLOGÍA Y CRITERIOS DE CLASIFICA- CIÓN}

El desarrollo de la investigación comenzó por la fase de documentación, tras la cual se pasó a la localización de las cerámicas en mejor estado para proceder a su estudio y obtención de los perfiles. Tras una observación preliminar se recogieron las morfologías básicas, posteriormente precisadas y ampliadas a través de la revisión metódica de unas mil piezas, tanto íntegras como fragmentos. Además, han sido consultadas tipologías y publicaciones sobre producciones de época andalusí y nazarí del arco mediterráneo de la península, así como de otros destacados centros bajomedievales de la Corona de Aragón, en especial los de Paterna y Manises, con el objetivo de establecer posibles precedentes y paralelos. En cuanto a los criterios considerados para el desarrollo de esta sistematización, éstos han sido los siguientes: tecnológicos, funcionales y morfológicos.

\section{CRITERIOS TECNOLÓGICOS}

\section{TIPOS DE PASTAS}

A través de una serie de analíticas arqueométricas realizadas a fragmentos esmaltados de entre los ss. XIII y XVI procedentes de excavaciones urbanas realizadas en la ciudad de Teruel, J. Pérez-Arantegui distingue tres tipos de pastas atendiendo a su porcentaje de contenido en calcio: pastas calcáreas $(10,5-16 \%)$, pastas poco calcáreas (entre 6-9\%) y pastas no-calcáreas (3\%) (PérezArantegui 2010: 405-406).

Por otra parte, a partir de un análisis macroscópico realizado a fragmentos procedentes de los fondos del Museo Provincial de Teruel, de cronología comprendida entre los ss. XIII y XV que presentaban alguna rotura reciente, han sido distinguidos cuatro tipos de pastas (fig. 1).

\section{TÉCNICAS DE CONFORMACIÓN}

Se distinguen tres técnicas de conformación en la cerámica estudiada: torneado, caracterizado por leves pero definidas estrías regulares presentes en las paredes de los recipientes; modelado a mano, que sirvió además como técnica auxiliar para la fabricación de elementos de sujeción y accesorios; y moldeado, al que se recurrió casi excepcionalmente.

\section{TIPOS DE COCCIÓN}

Atendiendo a la coloración de las pastas o superficie de los recipientes, se distinguen dos tipos de cocción: oxidante, con el resultado de pastas de tonos rojizos y rosados así como ocres y beiges, predominantes en el conjunto; y reductora, que tiene como consecuencia pastas de tonalidad grisácea, en ocasiones casi negruzcas. 


\begin{tabular}{|c|c|c|c|c|}
\hline & Color & Grano & Inclusiones & Otras observaciones \\
\hline Pasta A & Rojizo & Medio-fino & $\begin{array}{c}\text { Abundantes calizas de forma irregular y } \\
\text { tamaño variable }(0,5-3 \mathrm{~mm}) . \\
\text { Puntualmente presenta partículas } \\
\text { diminutas de mica plateada. }\end{array}$ & $\begin{array}{l}\text { No especialmente depurada. } \\
\quad \text { Vacuolas alargadas } \\
\text { Característica de la producción } \\
\text { esmaltada decorada en verde y } \\
\text { negro de los siglos XIII-XIV. }\end{array}$ \\
\hline Pasta B & Rojizo & Medio & $\begin{array}{l}\text { Cuarzos melados de forma angulosa y } \\
\text { tamaño variable }(0,5-2 \mathrm{~mm})\end{array}$ & $\begin{array}{c}\text { No muy compacta, } \\
\text { de aspecto hojaldrado. } \\
\text { Característica de los recipientes } \\
\text { de cocina a fuego. }\end{array}$ \\
\hline Pasta C & Rosado & Fino & $\begin{array}{l}\text { Intrusiones calizas blanquecinas y } \\
\text { beiges de pequeño tamaño, no } \\
\text { superando el milímetro. }\end{array}$ & $\begin{array}{l}\text { Más compacta y depurada que las } \\
\text { anteriores (A y B). } \\
\text { Característica de la producción } \\
\text { esmaltada decorada en verde y } \\
\text { negro de los siglos XIV-XV. }\end{array}$ \\
\hline Pasta D & Asalmonado-beige & Fino & $\begin{array}{l}\text { Inclusiones de tonos grises y ocres de } \\
\text { diminuto tamaño }(<1 \mathrm{~mm}) \text {, repartidos de } \\
\text { modo homogéneo. }\end{array}$ & $\begin{array}{c}\text { Depurada. } \\
\text { Vacuolas irregulares. } \\
\text { Característica de la producción } \\
\text { esmaltada decorada en azul. }\end{array}$ \\
\hline
\end{tabular}

Fig. 1: Descripción de las cuatro pastas diferenciadas y sus características.

\section{REVESTIMIENTOS}

Gran parte de las cerámicas estudiadas poseen cubierta vítrea, total o parcial. Esta tendría un doble propósito: funcional, como impermeabilizante de la superficie, y decorativo, mejorando el acabado de la pieza. Pueden distinguirse dos tipos de vedrío según su composición:

a) Vedrío plumbífero: formado por arena, sílice y óxido de plomo. Es traslúcido por sí mismo, concediendo a la superficie de las piezas un color que varía desde los tonos melados a gris pardo o verdoso.

b) Vedrío estannífero (o esmalte): en su composición, similar a la del anterior, destaca el óxido de estaño, el cual actúa como opacificante, generando una superficie blanca. La calidad del esmalte de las piezas turolenses varía del denso y cubriente al disuelto y traslúcido, en el que se emplearía una menor cantidad de óxido estannífero.

\section{TÉCNICAS DECORATIVAS}

En la cerámica bajomedieval de Teruel se aplicaron dos técnicas decorativas: la incisa y la pintada, ambas en la parte más visible de los recipientes, es decir, exterior de las formas cerradas e interior de las abiertas, que puntualmente recibieron también decoración en su exterior. A diferencia de la incisa, la decoración pintada, presente en la práctica totalidad de las piezas esmaltadas y que será objeto de una futura publicación, muestra una gran diversidad temática, abundando los motivos vegetales, heráldicos y geométricos. Dibujados en verde, verde y negro, negro o azul y distribuidos siguiendo, por lo general, esquemas basados en figuras geométricas, destacan sobre el fondo blanco proporcionado por el vidriado estannífero. Estas decoraciones, consideradas junto a la morfología de los objetos, han permitido la diferenciación y el establecimiento de diversas series en esta producción cerámica (Pérez-Piá 2018).

\section{CRITERIOS DE IDENTIFICACIÓN CONTEXTUAL- FUNCIONAL}

Si bien los rasgos formales de los propios recipientes ofrecen en muchos de los casos una idea aproximada de, al menos, uno de sus usos (Orton et al. 1997: 245-246), otro de los principales apoyos para la identificación del contexto de uso y atribución funcional ha sido la presencia de marcas o señales en las piezas, como restos de una repetida exposición al fuego directo o erosión y pérdida parcial del recubrimiento interno. A ello se añade la revisión de documentación; fuentes iconográficas bajomedievales; estudios de materiales coetáneos, como González-Martí (1944), Olivar (1952), Pascual y Martí (1986) y Mesquida (2001), entre otros; y el rastreo de posibles perduraciones etnográficas, en especial en aquellos casos en los que la identificación funcional se planteaba confusa.

\section{CRITERIOS DE IDENTIFICACIÓN MORFOLÓGICA}

Las dimensiones y morfologías concretas que presentan los objetos cerámicos permiten la diferenciación de 
formas e identificación de variantes (tipos y subtipos) en ellas. En este aspecto, procurando la máxima objetividad, para la identificación de las primeras se ha recurrido a índices como la relación entre diámetro máximo/altura, empleados en clasificaciones cerámicas de cronologías diversas (Orton et al. 1997: 175-177), incluida la planteada por J. Pascual y J. Martí sobre la verde-manganeso valenciana (1986), considerada con especial atención debido a su analogía respecto de la turolense. Para la distinción de tipos y subtipos, se ha valorado asimismo la presencia o ausencia de determinados elementos (de sujeción, un pico vertedor, etc.) que podrían condicionar el uso específico de la pieza sin modificar la función principal.

\section{CRITERIOS DE DEFINICIÓN Y DENOMINACIÓN DE LAS FORMAS}

Para la definición e ilustración de formas, tipos y subtipos se ha recurrido, siempre que ha sido posible, a piezas íntegras o restauradas bajo criterio arqueológico, la mayor parte de ellas depositadas en el Museo Provincial de Teruel y el Museu del Disseny de Barcelona. En aquellos casos puntuales en que no ha podido obtenerse un perfil se ha incluido en su lugar una fotografía; a excepción de las tinajas, forma de la que todavía no se cuenta con ninguna pieza completa ni fragmentos que aporten información considerable.
En cuanto a la denominación de las formas, debido a la insuficiencia de referencias y testimonios escritos medievales, se ha optado por recurrir a nombres del castellano actual que, de modo genérico, pueden identificarse con ellas, coincidiendo con la terminología tradicional de la cerámica. Los términos históricos que pueden ser asociados a una forma o tipo han sido referidos en su descripción general.

\section{PROPUESTA DE SISTEMATIZACIÓN}

En el caso de la cerámica bajomedieval de Teruel, el establecimiento de una tipología cerrada supondría dejar de lado tipos significativos que en la actualidad todavía cuentan con una insuficiente representación. En este sentido, pese a que la mayoría de formas, tipos y subtipos propuestos han sido definidos a partir de un conjunto de recipientes que comparten unas mismas características; algunos se encuentran basados en una única pieza. Sus particulares y distintivos rasgos, consecuencia de responder a un diferente uso, imposibilitaban su inclusión en cualquier otro grupo ya delimitado, dando lugar a su vez a su individualización.

Así, se ha planteado una sistematización abierta, que permita la ordenación de formas hasta ahora conocidas al tiempo que facilite la incorporación de nuevas a través de una codificación en la cual le ha sido asignado un número

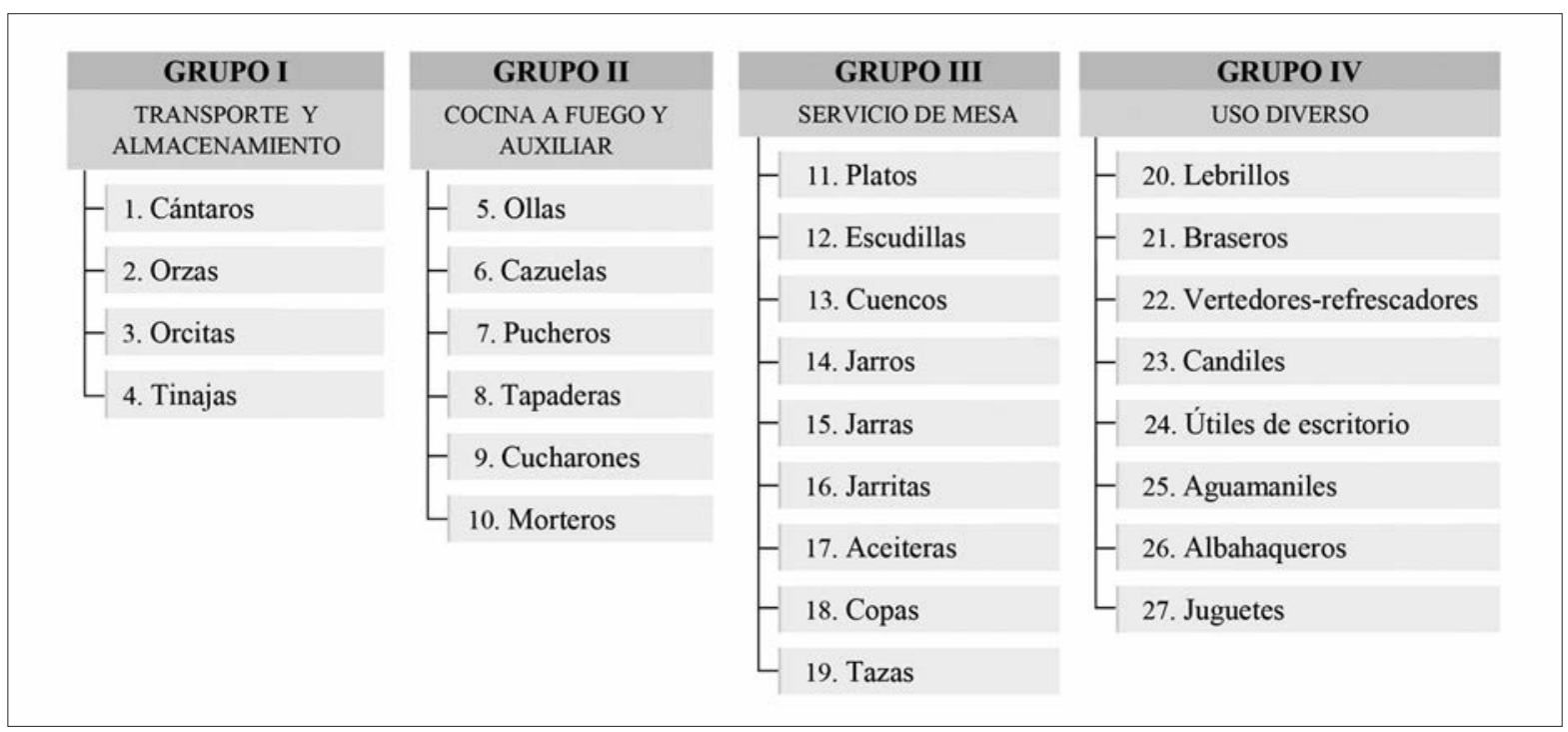

Fig. 2: Esquema de los grupos y formas identificadas. 
arábigo de modo correlativo a las formas, partiendo de la unidad; una letra del alfabeto latino a los tipos, comenzando siempre por la A; y un número (también arábigo) a los subtipos, partiendo de igual modo de la unidad.

Para un análisis y descripción de cada una de las formas lo más exhaustivo y homogéneo posible, al comentario de la función o funciones atribuidas y exposición de los rasgos morfológicos básicos le siguen la/s técnica/s de conformación, tratamiento de la superficie, decoración recibida, posibles precedentes y paralelos en otras zonas de la Corona de Aragón. En aquellas formas con tipos y subtipos se desarrolla, además, la descripción de sus particularidades.

Estructuralmente, la sistematización queda constituida en tres niveles:

1. Contextual-funcional. Se distinguen cuatro grandes grupos en base al contexto doméstico y de uso (transporte y almacenamiento, uso culinario, servicio de mesa y función diversa) que conforman el marco de la sistematización

2. Funcional-morfológico. Comprende un total de veintisiete formas (fig. 2), definidas según función y rasgos formales.

3. Morfológico. En él se identifican cincuenta y tres tipos y treinta y dos subtipos según diferencias en los rasgos formales que, sin afectar a la funcionalidad principal, suponen un cambio morfológico considerable.

\section{GRUPO I: CERÁMICA DE TRANSPORTE Y ALMA- CENAMIENTO (fig. 3)}

\section{CÁNTAROS}

Recipientes cerrados destinados al transporte o almacenaje de líquidos como el agua y el vino, conteniendo en ocasiones también ingredientes sólidos (González Martí 1944: 576). Presentan cuerpo ovoide, una o dos asas y base plana o convexa; oscilando entre 22 y $40 \mathrm{~cm}$ de altura.

Técnica de elaboración: a torno.

Tratamiento de la superficie: no presenta.

Decoración: acanaladuras y/o pintada en negro o granate, pudiendo prescindir de ellas.

Posibles precedentes: cántaros andalusíes, en especial los de época almohade (Bazzana 1990b: 152, fig. 36.257; Gibert et al. 1992: 142).

Paralelos en la Corona de Aragón: se trata de una forma abundante en la cerámica medieval levantina, con tipos casi idénticos y coincidentes en la decoración de peine de pinceles, como los producidos en Paterna (Amigues 1987: 171) o Zaragoza (Gutiérrez 2007: 305).
Tipos y subtipos:

1.A. Cuerpo ovoide en cuyos hombros apoyan dos asas de sección redonda.

1.A.1. Cuello recto desarrollado, borde potenciado al exterior de labio redondeado.

1.A.2. Cuello recto o levemente exvasado desarrollado, labio engrosado al exterior.

1.A.3. Cuello troncocónico invertido de boca ancha y labio biselado al interior.

1.B. Cuerpo ovoide, única asa vertical, cuello estrecho levemente exvasado y boca trilobulada con pico vertedor en eje con el asa. Podría corresponderse a la cantara con su piquo citada en un inventario zaragozano de finales del s. XV (González Martí 1944: 576).

\section{ORZAS}

Recipientes cerrados destinados al almacenamiento de líquidos (principalmente vino, agua y aceite) y sólidos. Consideradas como tinajas pequeñas (Coll 2009: 66), presentan un cuerpo ovoide o de tendencia globular, base plana y borde levemente exvasado que permitiría el acople de algún tipo de cierre de material flexible. Su altura total, comprendida entre 46,5 y $32,5 \mathrm{~cm}$, guarda una relación aproximada de 1:1 respecto del diámetro máximo.

Técnica de elaboración: a torno.

Tratamiento de la superficie: vedrío estannífero.

Decoración: pintada en verde y negro, negro o azul.

Posibles precedentes: tinajas o alfabías islámicas con cuerpos panzudos de tamaño medio (Bazzana 1990b: fig. 36.238; Rosselló 1978: fig. 20).

Paralelos en la Corona de Aragón: tanto en Barcelona como en el área valenciana se documentan tipos de gran semejanza (Beltrán 2006: 48; Coll 2009: 65-66).

Tipos y subtipos:

2.A. Cuerpo ovoide en cuya mitad superior se sitúan cuatro asas de cinta verticales y sección aplanada. Borde redondeado ligeramente exvasado.

2.B. Cuerpo de tendencia globular en su parte superior. Carece de asas y presenta un borde recto exvasado de labio biselado al interior.

\section{ORCITAS}

Recipientes cerrados destinados a contener y conservar ingredientes y alimentos de diversa naturaleza, como las orcetas de tener olivas recogidas en un inventario medieval turolense (Wittlin 1976: 198). De altura inferior a $20 \mathrm{~cm}$, presentan boca ancha que permitiría introducir y 
GRUPO I: CERÁMICA DE TRANSPORTE Y ALMACENAMIENTO

FORMA 1. Cántaros
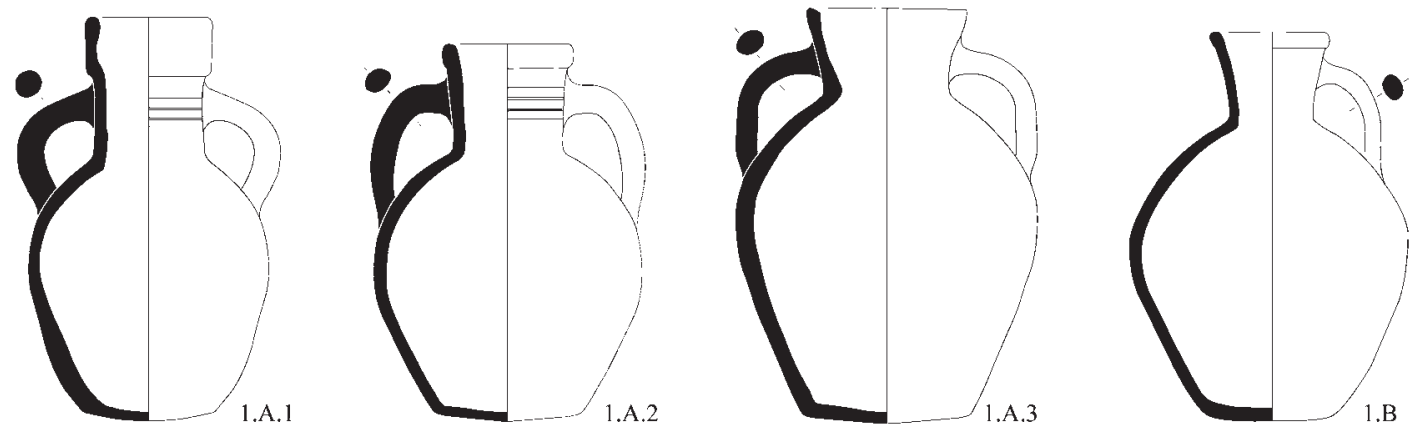

FORMA 3. Orzas
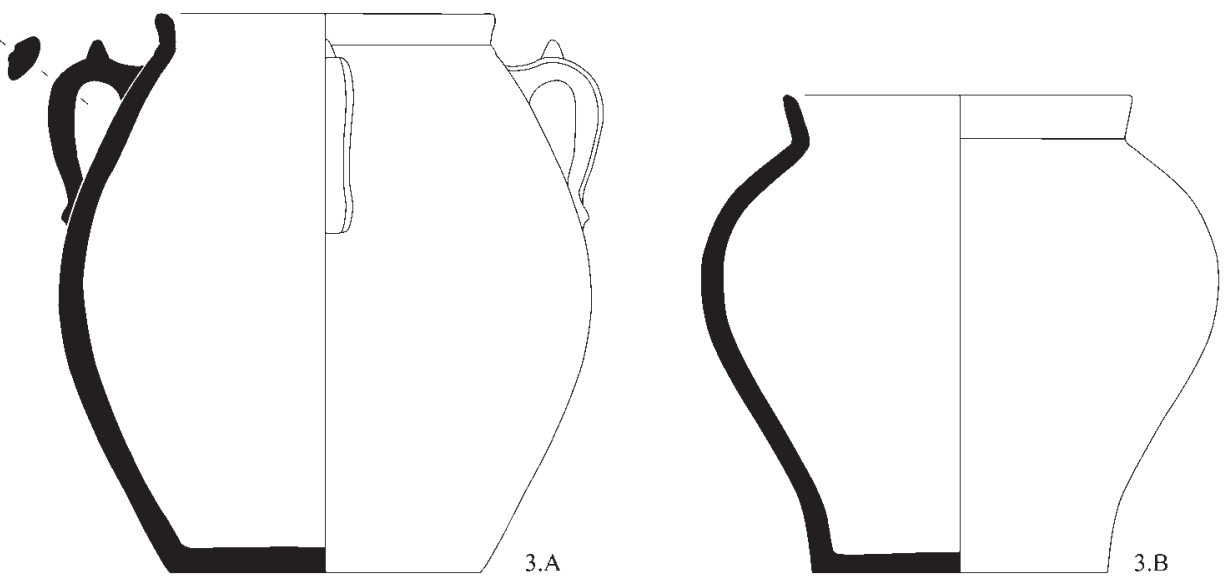

FORMA 4. Orcitas

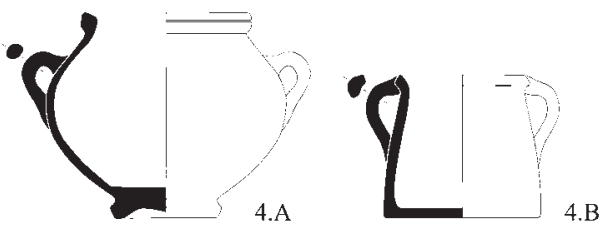

Fig. 3: GRUPO I: Cerámica de transporte y almacenamiento.

retirar su contenido con comodidad, dos asas verticales en el cuerpo y borde marcado al exterior para facilitar el ajuste de alguna cubierta.

Técnica de elaboración: a torno.

Tratamiento de la superficie: vedrío estannífero.

Decoración: pintada en verde y negro o negro.

Posibles precedentes: vasijas contenedoras andalusíes de pequeñas dimensiones y cuerpo globular (Bazzana 1990b: 151; Lerma et al. 1986: 158).
Paralelos en la Corona de Aragón: en Paterna y Manises se documentan las denominadas orsetas, con cuerpo globular de tendencia alargada y boca ancha de borde vuelto al exterior (González Martí 1944: fig. 341; Coll et al. 1988: 87, $\mathrm{n}^{\circ}$ 51).

Tipos y subtipos:

3.A. Cuerpo globular de paredes finas en cuyo hombro apoyan dos asas de sección redonda. Labio engrosado habitualmente acanalado y pie anular. 
3.B. Cuerpo troncocónico con dos asas verticales que parten del borde, ligeramente exvasado.

\section{TINAJAS}

Recipientes cerrados de gran tamaño empleados para almacenamiento de sólidos o líquidos. A pesar de que su fabricación fue recogida en el Forum Turolii, y de contar con abundantes referencias en escritos medievales, como las menciones a tinagas vinaderas (Wittlin 1976: 198), la ausencia de una pieza completa impide obtener un perfil de esta forma.

Tomando como referencia dos tinajas turolenses de cronología ligeramente posterior (Ortega 2002: lám. XLVIII) y otras coetáneas halladas en territorios peninsulares de la antigua Corona de Aragón; a esta forma se le presupone un cuerpo ovoide que podría alcanzar el metro de altura (ubicándose el diámetro máximo en la mitad superior), base plana, cuello corto y borde engrosado al exterior. El diámetro de boca podría estar condicionado por su contenido, siendo ancho para los sólidos y más estrecho en el caso de los líquidos. Del mismo modo, las destinadas a estos últimos probablemente contasen con algún orificio en la parte inferior del cuerpo para facilitar su vaciado.

Técnica de elaboración: combinación de torno y urdido.

Tratamiento de la superficie: no presenta.

Decoración: se desconoce.

Posibles precedentes: alfabías andalusíes de paredes convexas y base plana (Coll et al. 1988: 33; Rosselló 1978: 78).

Paralelos en la Corona de Aragón: ampliamente extendida por todo el territorio de la Corona aragonesa, esta forma se documenta en Zaragoza (Gutiérrez y De Miguel 2010: fig. 12), en el área valenciana (Pascual y Martí 1995: fig. 15.8; Amigues y Mesquida 1987: fig. 34), en la zona catalana y en Alicante (Menéndez 2005: 74, fig. 2).

\section{GRUPO II: CERÁMICA DE COCINA Y AUXILIAR} (fig. 4)

\section{II.A. CERÁMICA DE COCINA A FUEGO}

\section{OLLAS}

Recipientes cerrados destinados a la cocción de alimentos con abundante líquido. Presentan un cuerpo de paredes altas curvas, boca ancha y base levemente convexa. Su diámetro máximo, situado en la mitad de la panza, guarda una relación con la altura de 1:1, oscilando entre 12 y $20 \mathrm{~cm}$. Pueden contar con dos pequeñas asas verticales enfrentadas. Se identifican con el término marmita de los inventarios bajomedievales (Álvaro 1981: 102).

Técnica de elaboración: a torno.

Tratamiento de la superficie: vedrío plumbífero en interior que puede cubrir la zona exterior del borde.

Decoración: no presenta.

Posibles precedentes: ollas globulares de la tradición cerámica andalusí, con variedad de tipos hallados en territorios de la Marca Superior y Media andalusí (Esco y Sénac 1987: 146-147) y en el área valenciana (Coll et al. 1988: 23, 25; Martí y Pascual 1995: fig. 15.1).

Paralelos en la Corona de Aragón: ollas del NE y de las áreas aragonesa, catalana y valenciana, con asas y sin ellas. Han sido recuperados tipos análogos en Zaragoza (Gutiérrez y De Miguel 2010: fig. 19), Valencia (Coll et al. 1988: 90, $\mathrm{n}^{\circ}$ 58) y Paterna (Mesquida 2001: fig. 124, Martí et al. 2007: lám. 10).

Tipos y subtipos:

5.A. Cuerpo globular que puede presentar suaves acanaladuras horizontales, cuello cilíndrico y labio marcado al exterior y biselado al interior. Carece de elementos de sujeción.

5.B. Cuerpo ovoide o de tendencia bitroncocónica con dos asas de cinta que parten de la zona del borde y apoyan en el cuarto superior.

5.B.1. Paredes finas, borde desarrollado recto y exvasado. Asas de sección plana.

5.B.2. Moldura interior sobresaliente en la zona del labio, a modo de estribo en forma de $\mathrm{T}$, facilitando el ajuste de una tapadera. Asas de sección oval aplanada.

\section{CAZUELAS}

Recipientes abiertos para preparaciones culinarias que necesitasen de una menor cantidad de líquido, como caldos cortos o los sofritos (Ortega 2002: 143). Presentan cuerpos de paredes curvas con al menos un asa en el tercio superior y base plana. El término caçuela aparece en documentación medieval, especificándose su material de tierra y distinguida de los caçuelos por carecer de pico vertedor, como se refleja en un inventario aragonés de finales del s. XIV (González Martí 1944: 575).

Técnica de elaboración: a torno.

Tratamiento superficie: vedrío plumbífero en interior que en ocasiones reviste el exterior del borde y cuarto superior del cuerpo.

Decoración: no presenta. 
Posibles precedentes: al igual que para las cazuelas valencianas, podrían suponerse las ollas (Martí y Pascual 1995: 164), en una adaptación a las nuevas necesidades de uso y alimentarias.

Paralelos en la Corona de Aragón: aunque de profundidad menos acusada, cazuelas valencianas, especialmente las halladas en las Ollerías de Paterna, muestran rasgos semejantes, con paredes curvas de borde envasado y pico vertedor (Martí et al. 2007: lám. 10; Martí y Pascual 1995: fig. 15.2).

Tipos y subtipos:

6.A. Cuerpo de paredes curvas, borde carenado reentrante de labio redondeado y de una a dos asas en ángulo de $90^{\circ}$ respecto al pico vertedor, por el que respondería al caçuelo.

6.B. Cuerpo troncocónico invertido y borde exvasado. Podría contar con pico vertedor en eje con el asa.

\section{PUCHEROS}

Recipientes altos y cerrados destinados al guisado o cocido de alimentos. Cuerpo ovoide cuya altura total supera a la anchura, base plana, cuello apenas desarrollado y boca ancha que puede presentarse levemente trilobulada, contando con pico vertedor. En eje respecto a éste presenta un asa de cinta vertical que apoya en el hombro.

Técnica de elaboración: a torno.

Tratamiento de la superficie: vedrío de plomo en interior y cuarto superior exterior del cuerpo.

Decoración: no presenta.

Posibles precedentes: pucheros de la producción de cerámicas grises del NE peninsular, en su mayoría de la zona catalana, datados entre los ss. IX y XIV (Padilla 1984: 137).

Paralelos en la corona de Aragón: han aparecido tipos de gran semejanza entre el relleno de bóvedas góticas de algunas iglesias de Barcelona (Ríu y Ríu 1995: fig. 12.7).

\section{II.B. CERÁMICA AUXILIAR DE COCINA}

\section{TAPADERAS}

Objetos auxiliares asociados a otros recipientes, evitando la rápida evaporación del líquido en los destinados a la preparación de alimentos al fuego y contribuyendo a la conservación del contenido de orzas (Villanueva 2007: 274) o copas, en el caso de las más pequeñas (Ortega 2002: 154). Oscilan entre 6,5 y $14 \mathrm{~cm}$ de diámetro, con pedúnculo central a modo de asidero y un ala que descansaría en el borde del vaso asociado. En algunos textos medievales aparecen mencionadas con el término de cobertera (Álvaro 1981: 60-61).

Técnica de elaboración: a torno.

Tratamiento de la superficie: pueden presentar vedrío o carecer de cubierta.

Decoración: pintadas en negro o verde y negro.

Posibles precedentes: la influencia de la cerámica andalusí es evidente en esta forma, con una correspondencia que prueba su continuidad productiva (Bazzana 1990b: fig. 39.550; Gilbert et al. 1992: 159).

Paralelos en la Corona de Aragón: se conocen análogos en todo el territorio de la corona aragonesa, como los hallados en Manises y Paterna (Coll et al. 1988: 92, ${ }^{\circ}$ 61; Mesquida 1990a: lám. VI).

Tipos y subtipos:

8.A. Perfil convexo de paredes elevadas rectas o levemente curvas con una inflexión de la que parte un ala de labio redondeado. Asidero de botón central y base plana.

8.A.1. Paredes rectas que sobrepasan o igualan en altura al asidero. Ala plana o ligeramente inclinada.

8.A.2. Paredes altas que pueden presentarse levemente curvas con una leve artista de la que parte el ala. Base gruesa y asidero que sobresale en el perfil.

8.B. Perfil cónico, paredes gruesas rectas al exterior y levemente curvas al interior, terminadas en un ala corta apuntada. En la parte superior destaca un botón central macizo, de remate cónico o cóncavo. Pronunciada base anular de paredes biseladas al interior.

8.C. Perfil acampanado, paredes curvas que terminan en un ala inclinada. Agarrador central aplanado discoidal, cóncavo en su parte superior. Base anular apuntada a modo de engaste.

8.C.1. Ala recta desarrollada, terminada en un borde plano coincidente en altura con la base. Asidero con concavidad pronunciada.

8.C.2. Perfil más profundo. Ala corta apuntada y asidero de tendencia plana.

\section{CUCHARONES}

Utensilios destinados al servicio de preparaciones líquidas como caldos o sopas. Formados por un pequeño cuenco hemisférico unido a un grueso mango cilíndrico cuyo extremo libre, de terminación apuntada o redondeada, puede presentar un orificio.

Técnica de elaboración: a torno (cazoleta) y modelado a mano (mango).

Tratamiento de la superficie: vedrío estannífero.

Decoración: pintada en negro, pudiendo carecer de ella. 
GRUPO II: CERÁMICA DE COCINA Y AUXILIAR

II.a. CERÁMICA DE COCINAA FUEGO

FORMA 5. Ollas
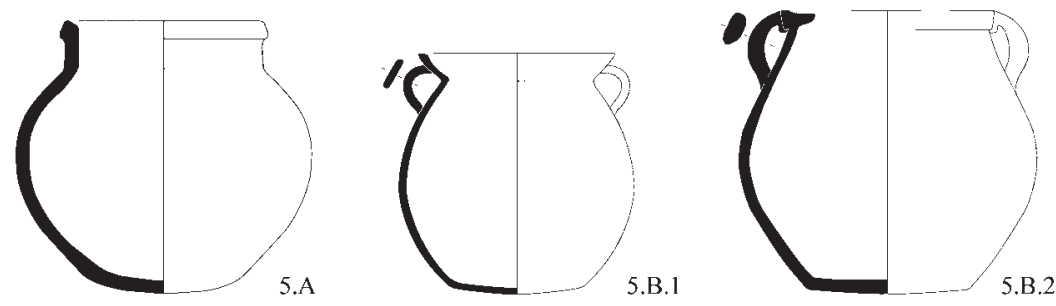

FORMA 6. Cazuelas
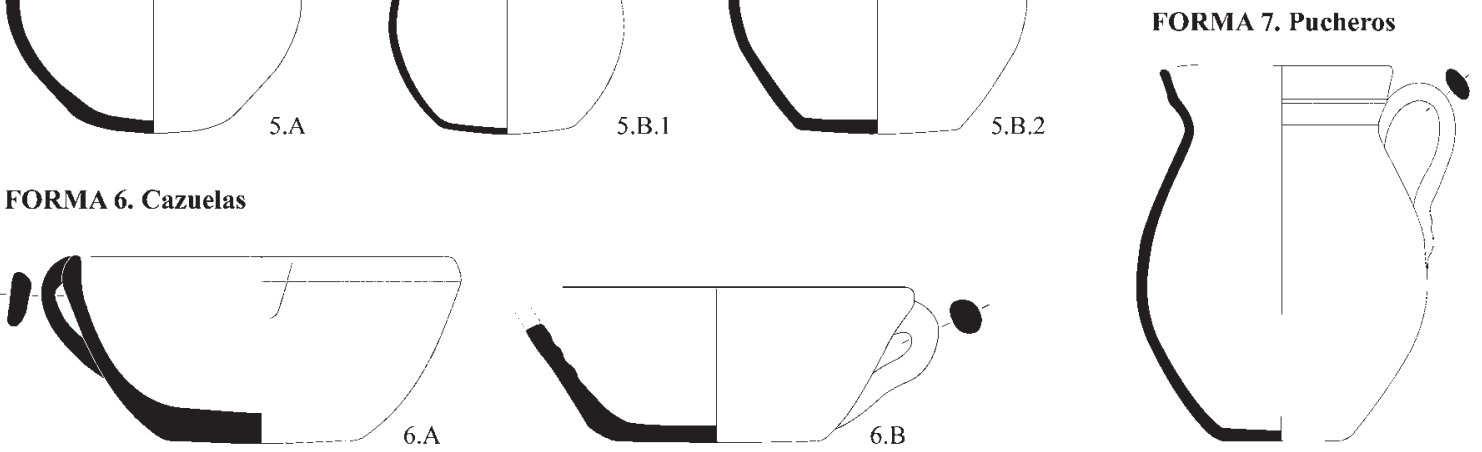

II.b. CERÁMICA AUXILIAR DE COCINA

FORMA 8. Tapaderas
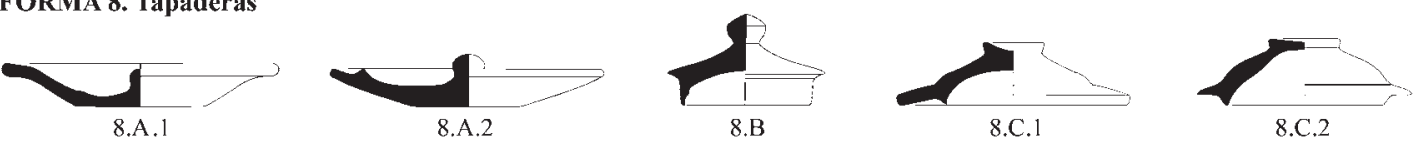

FORMA 9. Cazos
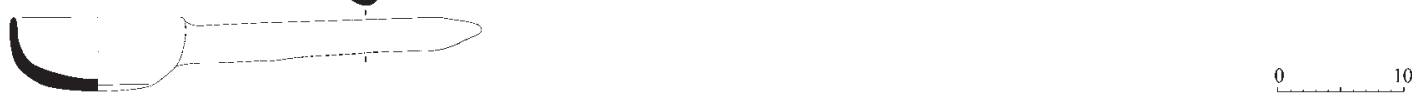

FORMA 10. Morteros

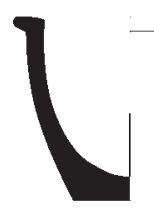

$10 \mathrm{~A}$

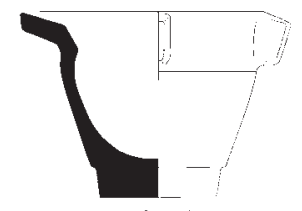

$10 . B .1$

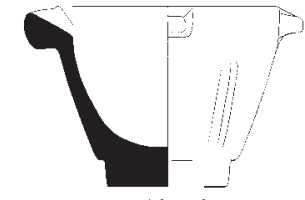

10.B.2

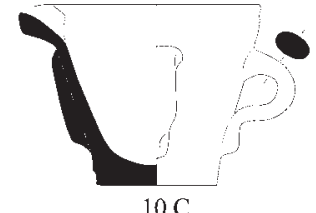

$10 . \mathrm{C}$

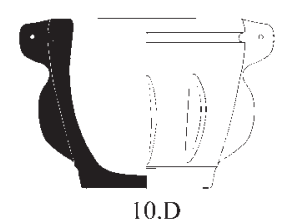

10.0

Fig. 4: GRUPO II: Cerámica auxiliar de cocina.

Posibles precedentes: se desconocen.

Paralelos en la Corona de Aragón: se desconocen.

\section{MORTEROS}

Recipientes destinados a la preparación de alimentos y salsas mediante el majado de ingredientes en su interior con la ayuda de un utensilio auxiliar, probablemente de madera. De cuerpo troncocónico, su diámetro máximo guarda una relación de 1:1 respecto de la altura. Fondo cóncavo y base maciza plana o levemente convexa de considerable espesor, destinada a soportar los repetidos golpes. Se corresponden con el término mámelot (Álvaro 1981: 99).

Técnica de elaboración: a torno.

Tratamiento de la superficie: vedrío estannífero.

Decoración: pintada en verde y negro.

Posibles precedentes: los almirez musulmanes, no muy frecuentes en la cerámica andalusí, y modelos metálicos de 
esta misma forma (Rosselló 1978: 74; Bazzana 1990b: 156, fig. 35.482).

Paralelos en la Corona de Aragón: se documentan tipos similares en Albarracín (Hernández y Franco 2004: 26-27), Barcelona (Ríu y Ríu 1995: fig. 12.7) y Paterna (Mesquida 2001: figs. 102 y 115).

Tipos y subtipos:

10.A. Paredes levemente curvas terminadas en una pequeña ala de labio redondeado.

10.B. Paredes rectas con tres asideros prismáticos en el borde. Pico vertedor de remate plano.

10.B.1. Grosor notablemente menor en la zona de la base. Asideros verticales.

10.B.2. Costillas de disposición vertical adosadas en el cuerpo y asideros horizontales.

10.C. Paredes rectas en las que al menos una de las costillas ha sido sustituida por un asa de cinta (con un máximo de tres), borde biselado al interior con pico vertedor en eje con una de las asas. Pie macizo diferenciado.

10.D. Paredes curvas al interior y rectas al exterior, donde presenta costillas adosadas. En el borde se sitúan dos asideros verticales perforados.

\section{GRUPO III: CERÁMICA DEL SERVICIO DE MESA (figs. 5 y 6 )}

\section{PLATOS}

Recipientes abiertos destinados al servicio y consumo de alimentos en la mesa de modo individual o colectivo. Presentan cuerpo de perfil bajo, paredes rectas o ligeramente curvas y una habitual leve concavidad en su centro. Su diámetro máximo oscila entre 13,5 y $44,5 \mathrm{~cm}$, con una relación entre éste y la altura superior al valor de 3,5.

Técnica de elaboración: a torno, incluyendo el moldeado para el tipo E.

Tratamiento de la superficie: vedrío estannífero en el interior, ocasionalmente puede cubrir la mitad superior de su exterior.

Decoración: pintada en verde y negro, negro o en azul.

Posibles precedentes: casi inexistente en la cerámica andalusí e igualmente inusual entre las primeras cerámicas bajomedievales producidas bajo domino cristiano, de esta forma se conocen modelos fabricados en madera, en los que podrían haberse basado los alfareros (Coll et al. 1988: 31).

Paralelos en la Corona de Aragón: se documentan tipos análogos en Zaragoza (Ortega 2002: 266, n 110; De
Sus Giménez 2003: 365) así como en Manises y Paterna (Olivar 1952: 80; Pascual y Martí 1986: figs. 87-89).

Tipos y subtipos:

11.A. Paredes continuas rectas o levemente curvas con leve inflexión en el tercio superior y pie anular.

11.A.1. Borde exvasado que sobresale en una moldura de labio redondeado. Pie anular y diámetro máximo situado en torno a los $15 \mathrm{~cm}$.

11.A.2. Borde reentrante y diámetro máximo de entre 20 y $36,5 \mathrm{~cm}$ Se identifica con los tallatorios o tajadores, en los que se servía y cortaba la carne (Álvaro 1981: 141).

11.B. Paredes de tendencia recta, borde vuelto y pie anular. Adosadas a la superficie interior presenta cinco pequeños receptáculos cilíndricos (uno central rodeado por los cuatro restantes), elaborados con tiras de pasta.

11.C. Paredes exteriores rectas, labio redondeado y base plana. Presenta un diámetro máximo de entre 16 y $25 \mathrm{~cm}$.

11C.1. Paredes continúas al interior y fondo llano o levemente cóncavo.

11.C.2. Inflexión hacia la mitad interior del cuerpo, de la que parte un ala ancha.

11.D. Paredes ligeramente curvas con ligera inflexión en el tercio superior de la que parte un ala recta inclinada de borde redondeado. Umbo realizado a molde. Su diámetro máximo suele oscilar entre 30 y 44,5 cm.

\section{CUENCOS}

Recipientes abiertos destinados al servicio de alimentos y de utilización tanto individual como colectiva, que variaría en función de su tamaño. Presentan cuerpos por lo general de tendencia hemisférica y pie anular que puede contar con una perforación, habitual en aquellos dotados de ala. La relación entre diámetro máximo y altura oscila entre 2,5 y 3,5 .

Técnica de elaboración: a torno.

Tratamiento de la superficie: vedrío estannífero en interior.

Decoración: pintada en verde o verde y negro. Excepcionalmente estrías en el exterior.

Posibles precedentes: ataifores y jofainas andalusíes, formas que tras la conquista pasaron a formar parte habitual del repertorio cerámico cristiano (Coll et al. 1988: 29, 31-32).

Paralelos en la Corona de Aragón: recipientes de morfologías y decoraciones prácticamente idénticas fabricados en Paterna (Pascual y Martí 1986: figs. 10, 18). 
GRUPO III: CERÁMICA DEL SERVICIO DE MESA (I)

FORMA 11. Platos
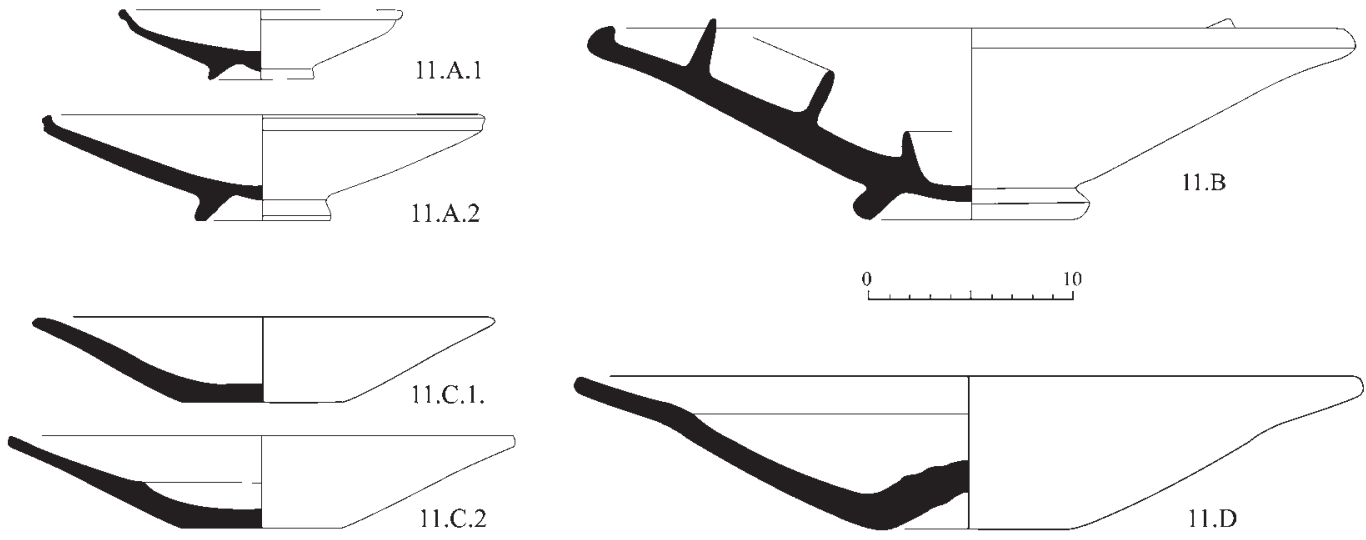

FORMA 12. Cuencos
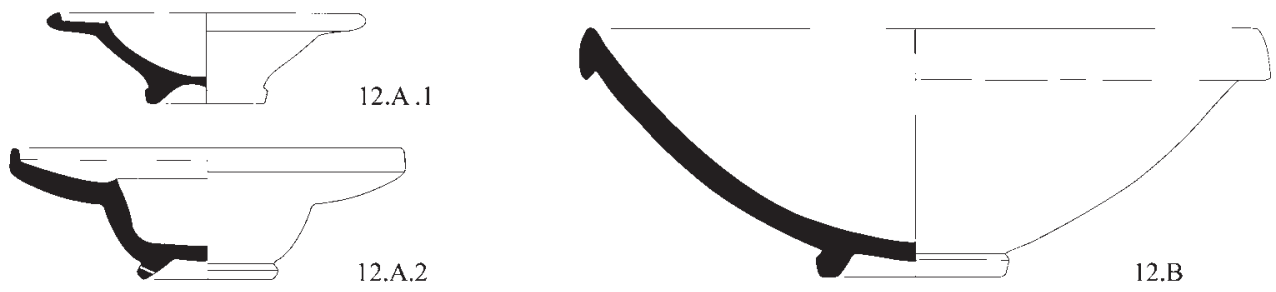

FORMA 13. Escudilllas
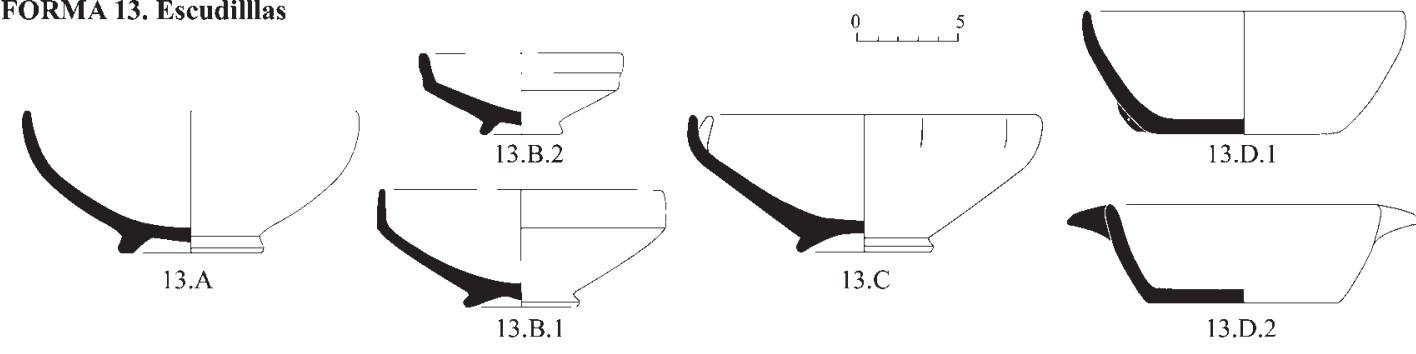

13.D.1

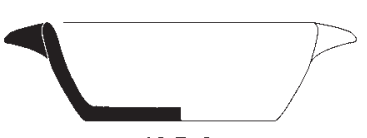

Fig. 5: GRUPO III: Cerámica del servicio de mesa. Formas 11-13.

Tipos y subtipos:

12.A. Compuesto por un receptáculo central cuyo borde se prolonga en un ala recta.

12.A.1. Cazoleta hemisférica terminada en ala horizontal con doble reborde.

12.A.2. Cazoleta de paredes ligeramente curvas de tendencia recta y fondo plano o convexo. Ala inclinada de borde elevado y labio redondeado.

12.B. Perfil de tendencia hemisférica y borde de labio vuelto caído, con diámetro máximo en torno a $30 \mathrm{~cm}$.

\section{ESCUDILLAS}

Recipientes abiertos destinados al consumo de preparaciones líquidas o semisólidas y bebidas. Presentan un cuerpo de paredes curvas o rectas con inflexión y una relación de diámetro máximo y altura de 2 a 3. Coincidiendo en el rango de 2,5 a 3 con la forma anterior, han sido definidas como escudillas aquellas piezas cuyo diámetro de boca se encuentra comprendido entre 9 y $16 \mathrm{~cm}$, entendiendo que esta medida responde al uso individual asignado tradicionalmente a dicha forma (González Martí 
GRUPO III: CERÁMICA DEL SERVICIO DE MESA (II)
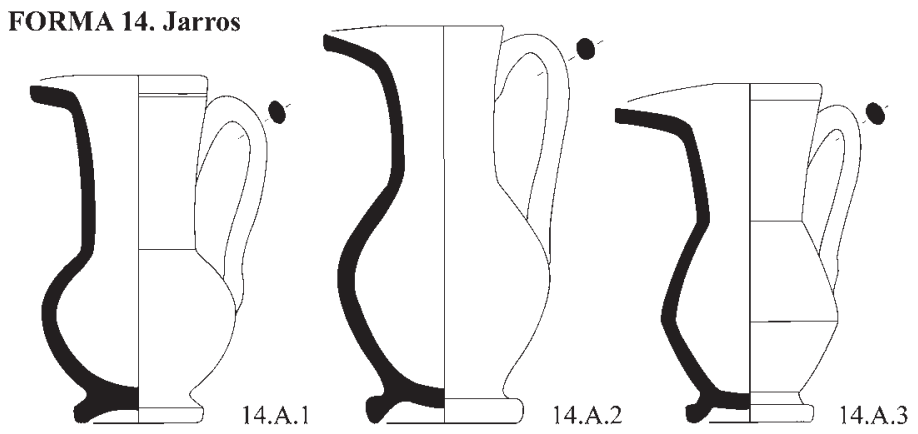

FORMA 15. Jarras
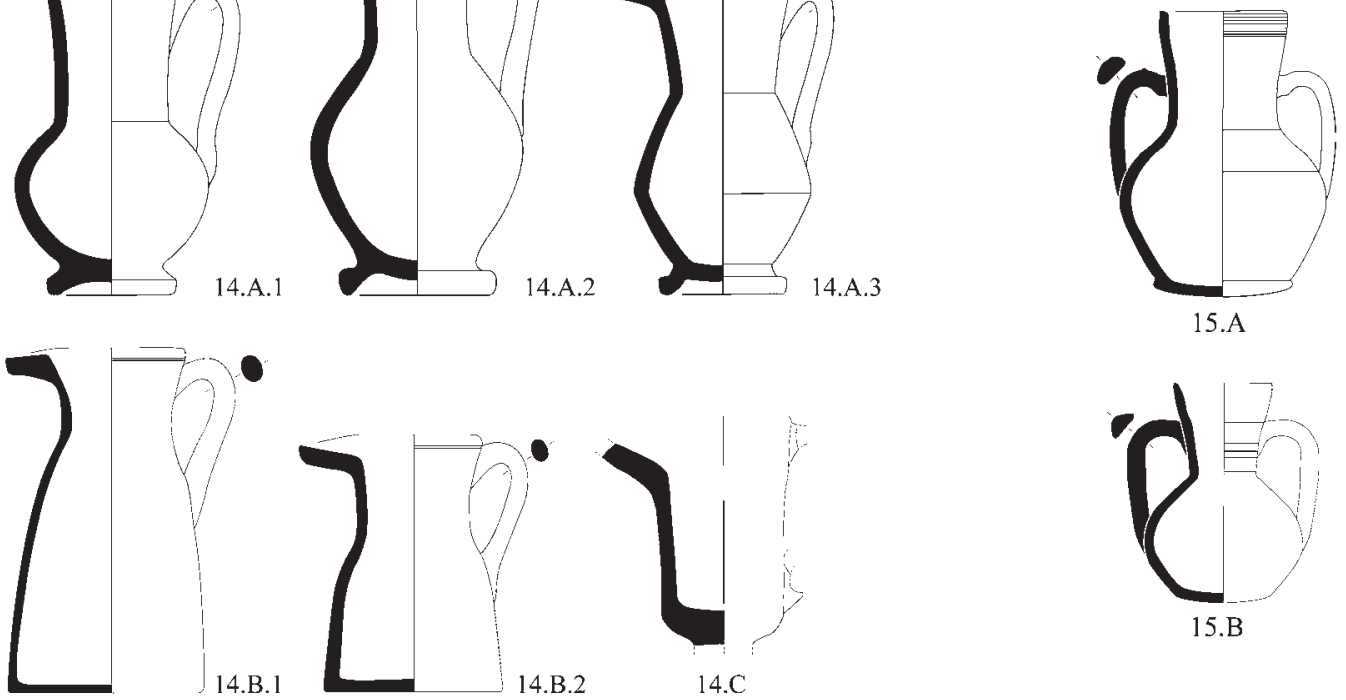

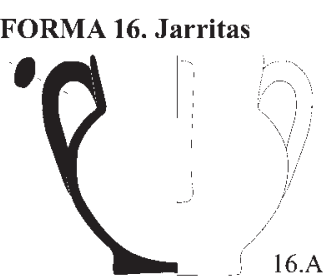

FORMA 17. Aceiteras

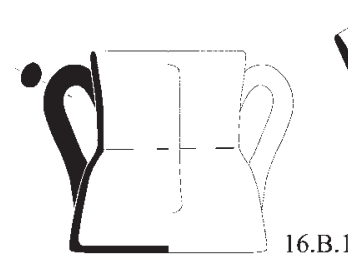

16.B.

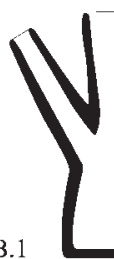

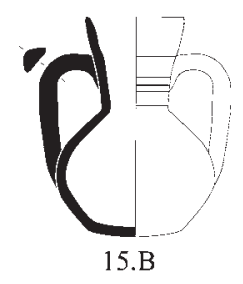
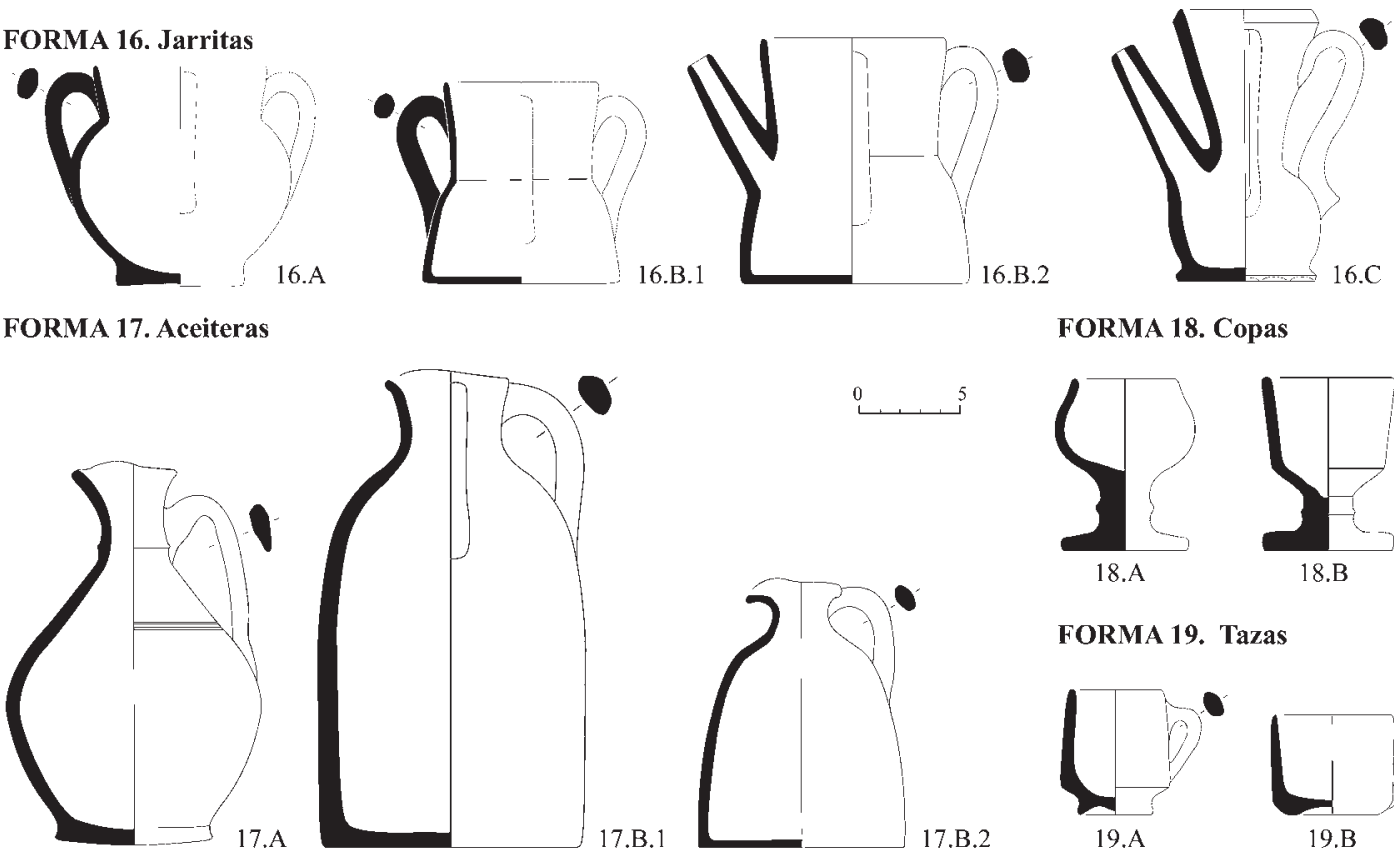

FORMA 18. Copas
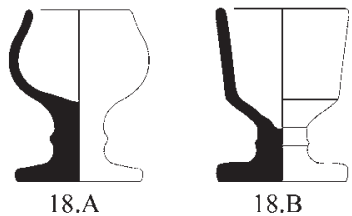

FORMA 19. Tazas

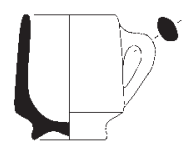

19.A

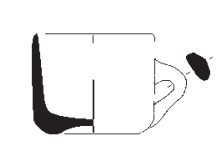

19.B

Fig. 6: GRUPO III: Cerámica del servicio de mesa. Formas 14-19.

1944: 584). Aparecen repetidamente citadas en inventarios medievales desde el s. XIV, predominando el término escudiellas (Álvaro 1981: 74-75).

Técnica de elaboración: a torno.
Tratamiento de la superficie: vedrío estannífero. Decoración: verde y negro, verde, negro o azul.

Posibles precedentes: ataifores y cuencos andalusíes (Rosselló 1978: 16-18; Coll et al. 1988: 31). 
Paralelos en la Corona de Aragón: han sido documentados ejemplares de gran semejanza en Zaragoza (Gutiérrez y De Miguel 2010: fig. 4) y en toda el área valenciana (Pascual y Martí 1986: figs. 11-16).

Tipos y subtipos:

13.A. Perfil hemisférico, paredes curvas continuas, terminadas en un borde redondeado recto o reentrante de labio ligeramente engrosado o biselado. Pie anular.

13.B. Perfil carenado en su tercio superior, paredes de tendencia recta y pie anular que puede estar perforado. De la inflexión, pronunciada al exterior mediante una arista o moldura, parte un borde recto levemente exvasado o invasado terminado en labio redondeado o apuntado.

13.B.1. Cuerpo de tendencia hemisférica en su interior y paredes rectas al exterior. Puede presentar moldura exterior en la zona de inflexión.

13.B.2. Cuerpo de paredes gruesas y tendencia recta, con marcada inflexión. Su altura está comprendida entre 3,5 y $4 \mathrm{~cm}$, con un diámetro máximo que en ningún caso excede los $9,5 \mathrm{~cm}$. Excepcionalmente puede presentar pie macizo.

13.C. Paredes rectas con una inflexión en su parte superior de la que parte un borde reentrante polilobulado moldeado (de entre cinco a ocho lóbulos). Pie anular. Las más antiguas podrían presentar dos pequeñas asitas adosadas (Hernández Pardo 2014: fig. 6.23).

13.D. Base plana o levemente convexa, paredes exvasadas de tendencia recta y fondo llano.

13.D.1. Borde recto o ligeramente invasado de labio redondeado. En el exterior suele contar con un pequeño apéndice perforado, situado en la inflexión entre la base y las paredes.

13.D.2. Cuenta con dos pequeños asideros horizontales (orejetas) enfrentados en la zona del borde.

\section{JARROS}

Recipientes cerrados y profundos destinados a servir líquidos en la mesa, principalmente agua o vino (Ortega 2012: 54). Cuerpos de perfil diverso con cuello de paredes rectas levemente exvasado y boca con pico vertedor. En eje con éste, una única asa de cinta vertical que arranca en el borde. Presentan una altura total comprendida entre 10 y $35 \mathrm{~cm}$. Se corresponde con los términos medievales de pichel o picher (Álvaro 1981: 93, 119, 122).

Técnica de elaboración: a torno.

Tratamiento de la superficie: vedrío estannífero.
Decoración: pintada en verde, verde y negro, negro o azul. Puede presentar incisiones, estrías o acanaladuras en la zona del cuerpo y borde.

Posibles precedentes: contenedores de líquidos de cuerpo globular con una sola asa y piquera de época andalusí (Rosselló 1978: 40-43). Por otra parte, el pie alto del tipo C podría responder a la imitación de modelos existentes en la vajilla de metal (Ortega 2012: fig. 7).

Paralelos en la Corona de Aragón: se documentan recipientes de gran parecido en Paterna, predominando el cuerpo globular (Mesquida 2001: láms. 26-28), y en Manises, incluyendo de cuerpo cilíndrico o campaniforme (Coll 2009: fig. 133; González Martí 1944: fig. 548).

Tipos y subtipos:

14.A. Cuello largo ligeramente exvasado que termina en un borde de labio redondeado. Pico vertedor desarrollado en eje con el asa de cinta vertical que apoya en el hombro. Pie anular.

14.A.1. Cuerpo globular o esferoide achatado, cuello ancho y de altura superior al cuerpo.

14.A.2. Cuerpo ovoide, cuello que suele presentar una altura semejante a la del cuerpo.

14.A.3. Cuerpo bitroncocónico con marcada inflexión en la parte central.

14.B. Cuerpo acampanado o de tendencia cónica, cuello levemente exvasado y base plana.

14.B.1. Cuerpo acampanado o de tendencia cónica con un cuello ancho.

14.B.2. Cuello destacado, cuerpo con hombro marcado. Su altura no supera $\operatorname{los} 21 \mathrm{~cm}$.

14.C. Cuerpo tubular con paredes levemente exvasadas en la mitad superior, donde arranca el pico vertedor, de desarrollo vertical. Pie alto, no conservado en ninguno de los ejemplares.

\section{JARRAS}

Recipientes cerrados y profundos destinados a contener y servir líquidos. Presentan cuerpo globular y cuello exvasado destacado del que parten dos asas de cinta. Base levemente convexa que puede ser moldurada. $\mathrm{Su}$ altura oscila entre 14,5 y $23 \mathrm{~cm}$.

Técnica de elaboración: a torno.

Tratamiento de la superficie: vedrío plumbífero.

Decoración: estrías o acanaladuras horizontales en el cuerpo, cuello o borde.

Posibles precedentes: jarras y jarritas islámicas con cuerpo globular y dos asas (Bazzana 1990b: fig. 37.345). 
Paralelos en la Corona de Aragón: se conocen tipos parecidos en Paterna (Amigues 1987: fig. 5; Martí et al. 2007: 155).

Tipos y subtipos:

15.A. Cuerpo globular de tendencia achatada y base moldurada.

15.B. Cuerpo globular, borde destacado de labio biselado al interior.

\section{JARRITAS}

Recipientes de forma cerrada cuya función principal sería el consumo comunitario de líquidos en la mesa, como parece apuntar su boca ancha y la presencia de múltiples asas (Ortega 2012: 59-60), además de para su servicio, en especial los dotados de largo caño. De altura inferior a $18 \mathrm{~cm}$, presentan cuerpos globulares o de tendencia campaniforme, cuello y borde ligeramente exvasados y asas verticales de cinta que apoyan en los hombros.

Técnica de elaboración: a torno.

Tratamiento de la superficie: vedrío estannífero.

Decoración: pintada en verde y negro.

Posibles precedentes: jarritas almohades y almorávides de perfil globular o bitroncocónico, cuello ancho y asas de cinta (Bazzana 1990b: fig. 37.342-343; Rosselló 1983: figs. 4-5). La base plana dodecagonal del tipo C y su morfología respondería a la influencia de formas metálicas coetáneas (Ortega 2012: fig. 9).

Paralelos en la Corona de Aragón: se documentan tipos muy similares en Paterna (Amigues 1986b: 53; Pascual y Martí 1995: 168, fig. 15.4).

Tipos y subtipos:

16.A. Cuerpo globular o bitroncocónico, cuello ligeramente exvasado del que parten de dos a cuatro asas de cinta, borde recto y pie anular o convexo.

16.B. Cuerpo campaniforme achatado y cuello recto destacado que puede igualar al cuerpo en altura. Base plana, donde presenta su diámetro máximo.

16.B.1. Dos o cuatro asas en cinta que apoyan en el hombro.

16.B.2. Tres asas, largo pitorro que parte de la inflexión entre cuerpo y cuello.

16.C. Pequeño cuerpo globular al que se une un destacado cuello troncocónico invertido de labio biselado. Largo caño situado en la inflexión entre ambas partes y de una a tres asas de cinta vertical. Pie destacado dodecagonal, retocado a cuchillo antes de la primera cocción.

\section{ACEITERAS}

Recipientes cerrados destinados a contener y servir el aceite. De perfiles diversos, presentan cuello cilíndrico estrecho, asa o asas de cinta vertical, boca trilobulada con pico vertedor y base levemente convexa o plana. En textos medievales aragoneses, en su mayoría inventarios, aparecen mencionadas como alcuzas y olieras (Álvaro 1981: 15).

Técnica de elaboración: a torno.

Tratamiento de la superficie: vedrío plumbífero o vedrío estannífero.

Decoración: pintada en verde y negro o en azul. Acanaladuras.

Posibles precedentes: redomas andalusíes de cuerpo abombado y boca trilobulada, como las documentadas en Zaragoza (Gutiérrez y De Miguel 2010: fig. 8) y el arco mediterráneo peninsular (Coll 2009: 50, figs. 77-78).

Paralelos en la Corona de Aragón: análogos al tipo A de la zona valenciana (Martí et al. 2007: lám. 15.4).

Tipos y subtipos:

17.A. Cuerpo piriforme, base maciza moldurada ligeramente convexa y asa de sección plana que parte del cuello y se apoya en el hombro.

17.B. Cuerpo cuyo diámetro máximo se sitúa en la base plana.

17.B.1. Cuerpo cilíndrico al que se adosan de una o tres asas de sección ovalada que parten de la zona del borde o cuello. Presenta alturas comprendidas entre 30 y $40 \mathrm{~cm}$ por lo que su uso se restringiría más al almacenamiento que al servicio.

17.B.2. Cuerpo campaniforme con una única asa situada en eje respecto al pico vertedor. Altura media de $15 \mathrm{~cm}$.

\section{COPAS}

Recipientes destinados al consumo individual de líquidos en la mesa. De morfologías diversas, se componen de un pequeño cuenco o vaso unido a una base plana circular mediante un vástago moldurado. Podrían llevar asociada una tapadera o cobertera como elemento auxiliar (Ortega 2002: 295, n 167).

Técnica de elaboración: a torno.

Tratamiento de la superficie: vedrío estannífero.

Decoración: pintada en verde y negro, negro o sin decoración.

Posibles precedentes: prototipos medievales metálicos (Coll et al. 1988: 32).

Paralelos en la Corona de Aragón: piezas de perfiles semejantes en el área valenciana (Pascual y Martí 1986: fig. 22). 
Tipos y subtipos:

18.A. Cuerpo esférico con pequeño borde recto y labio redondeado.

18.B. Cuerpo de paredes rectas, ligeramente exvasadas.

\section{TAZAS}

Recipientes cerrados destinados al consumo individual de líquidos en la mesa. Formados por un cuerpo tubular de paredes rectas al que se le añade un asa de cinta de sección aplanada. Las dimensiones, que no superan los 7,5 cm tanto en altura como en diámetro máximo, muestran una reducida capacidad que respondería al uso individual.

Técnica de elaboración: a torno.

Tratamiento de la superficie: vedrío estannífero.

Decoración: pintada en verde y negro o en azul.

Posibles precedentes: tazas andalusíes producidas entre el s. XII y principios del XIII, con tipos muy semejantes entre las halladas en el arrabal meridional de Zaragoza (Gutiérrez y De Miguel 2010: 433-434, fig. 7).

Paralelos en la Corona de Aragón: en Paterna se documentan recipientes de perfiles similares (Amigues y Mesquida 1987: 56).

Tipos y subtipos:

19.A. Paredes rectas ligeramente invasadas, labio redondeado, fondo convexo y pie anular.

19.B. Paredes rectas verticales o levemente exvasadas, labio apuntado, base convexa o plana. Boca más ancha y perfil menos profundo. No supera $\operatorname{los} 6 \mathrm{~cm}$ de altura.

GRUPO IV: CERÁMICA DE USO DOMÉSTICO DIVERSO (fig. 7)

\section{LEBRILLOS}

Recipientes abiertos de uso múltiple como lavado y preparación de alimentos, la colada e incluso para la higiene personal, teniendo en cuenta sus cuidados acabados y decoraciones. Presentan cuerpo troncocónico invertido de perfil alto y paredes rectilíneas que terminan en un ala corta de labio redondeado. Con diámetros máximos que sobrepasan los $60 \mathrm{~cm}$, en contraste con los $22 \mathrm{~cm}$ del más pequeño, sus dimensiones se adecuarían a la función.

Técnica de elaboración: a torno.

Tratamiento de la superficie: vedrío estannífero en el interior y ocasionalmente en el exterior.

Decoración: pintada en verde y negro o negro.
Posibles precedentes: alcadafes andalusíes (Coll et al. 1988: 36).

Paralelos en la Corona de Aragón: se documentan tipos muy similares en Zaragoza (Gutiérrez y De Miguel 2010: 440, fig. 13) y Paterna (Pascual y Martí 1995: fig. 15.11).

Tipos y subtipos:

20.A. Paredes gruesas, con fondo y base planos.

20.B. Paredes finas, fondo ligeramente cóncavo y pie anular; habitualmente perforado.

\section{BRASEROS}

Recipientes abiertos de funcionalidad diversa. Contendrían sólidos y líquidos, pudiendo haber servido también como aguamanos (Mesquida 1990a: 6). Cuerpo troncocónico invertido de perfil bajo, borde rematado en un ala recta inclinada y fondo y base planos.

Técnica de elaboración: a torno.

Tratamiento de la superficie: vedrío estannífero en el interior.

Decoración: pintada en verde y negro.

Posibles precedentes: alcadafes almohades de perfil bajo (Coll et al. 1988: 68).

Paralelos en la Corona de Aragón: platos braseros, producidos especialmente en Manises durante el s. XV (Coll 2009: fig. 167).

\section{VERTEDORES-REFRESCADORES}

El único ejemplar conocido de esta forma presenta un cuerpo cilíndrico de base plana cubierto por un casquete hemisférico. En la unión entre ambas partes se dispone un caño tubular de dimensiones destacadas, de cuya mitad surge un asa-puente que apoya en la zona superior de la cubierta. En cuanto a su función, se ha apuntado al de refrescador, conteniendo hielo destinado a enfriar las bebidas (Ortega 2002: 260). No obstante, dada la particular morfología y pequeño tamaño de esta pieza, unido a la presencia de vidriado, quizá cabría considerar además su posible uso como vertedor del aceite para rellenar los candiles, en una línea semejante al askós griego (Gómez y Pérez-Ballester 2004: 32).

Técnica de elaboración: a torno.

Tratamiento de la superficie: vedrío estannífero.

Decoración: pintada en negro.

Posibles precedentes: se desconocen.

Paralelos en la Corona de Aragón: se documentan piezas similares, vinculadas a la contención de aceite, en el área catalana (Bolòs et al. 1986: fig. 4.46, 698). 


\section{CANDILES}

Destinados a la iluminación de las estancias del hogar, presentan formas diversas, con al menos una cazoleta abierta con uno o varios picos para situar la mecha y en cuyo interior se situaría el combustible. Algunos tipos se dotaron de un asa o asidero que permitía fácilmente su trasporte.

Técnica de elaboración: a torno.

Tratamiento de la superficie: vedrío estannífero.

Decoración: pintada en verde y negro, pudiendo carecer de ella.

Posibles precedentes: candiles andalusíes, especialmente almohades, como los recuperados en Albarracín (Sánchez-Lafuente 1981: 172-173).

Paralelos en la Corona de Aragón: forma frecuente en el área valenciana (González Martí 1944: fig. 319; Pascual y Martí 1986: fig. 23, Mesquida 1990b: 35, 52). Del tipo D se conocen análogos en Barbastro (Juste y Motis 2014: 29), Calatayud (Cebolla et al. 2009: 11) y Lérida (Pomares 1985: 488), relacionados con las juderías.

Tipos y subtipos:

23.A. Cazoleta abierta con piquera de pellizco. Base plana o pie anular.

23.B. Cazoleta de una o varias piqueras situada sobre un vástago vertical cilíndrico moldurado que apoya sobre base circular de borde elevado. Presenta un asa de cinta vertical que parte del exterior de la cazoleta hasta la base. Por su morfología puede asociarse con el candil de pie alto, tipo de tradición andalusí (Bazzana 1990b: 157, fig. 39.630).

23.C. Soporte cónico hueco, desprovisto de base y al que se unen de cuatro a cinco cazoletas de pellizco mediante vástagos cilíndricos, sobre los que apoyan en su parte inferior. Los dos ejemplares conservados carecen de la parte superior del soporte, que quizá se rematase por algún tipo de cogedor.

23.D. Pequeñas cazoletas de pellizco dispuestas de manera contigua sobre una base rectangular de acusada tendencia longitudinal. Probablemente contase con un total de ocho cazoletas de pequeño tamaño y una de mayores dimensiones en el extremo que se ha perdido. Pese a que ningún ejemplar se conserva íntegro, sus rasgos y aparición en la zona de la judería remiten a la hanukkiya, lámpara empleada en la Hannuká o Festival de las luces judío (Muñoz 2002: 170). De ser así, debería añadirse la función ritual y religiosa.

\section{4. ÚTILES DE ESCRITORIO}

Recipientes cuya función consistiría en contener materiales empleados en la escritura durante época bajomedieval, fundamentalmente tinta y plumas. De morfologías diversas, presentan en común pequeñas concavidades y estrechos y profundos orificios cilíndricos.

Técnica de elaboración: a torno, con partes destacadas modeladas a mano.

Tratamiento de la superficie: vedrío estannífero

Decoración: pintada en verde y negro.

Posibles precedentes: tinteros de época califal andalusí, de cuerpos de tendencia cilíndrica o cúbica con cavidad central de reducida capacidad, con ejemplares conocidos en Valencia y en el S peninsular (Coll 2009: 47; Zozaya y Llagosteras 1977: 912).

Paralelos en la Corona de Aragón: tinteros de la zona valenciana, decorados en verde y negro y cuya forma se asemeja al tipo A (Pascual y Martí 1986: fig. 33).

Tipos y subtipos:

24.A. Cuerpo paralepípedo dotado con un reducido depósito cilíndrico en uno de sus lados, orificios en la parte superior central y base plana.

24.B. Cuerpo de altura comprendida entre 20 y 23,5 $\mathrm{cm}$, con receptáculos tubulares sobre una base provista de pequeñas concavidades y orificios cilíndricos. Considerados como escribanía por la complejidad y multiplicidad de espacios con diferentes fines (Padilla et al. 2002: 48).

24.B.1. Cuerpo de base cuadrada dividida longitudinalmente en dos por una pared retocada a cuchillo. En la mitad delantera presenta dos pequeñas oquedades cilíndricas mientras que en la trasera se sitúan dos botes tubulares de labio igualmente retocado a cuchillo, unidos entre sí y a las paredes laterales mediante asas puente.

24.B.2. Reproduce la estructura de un castillo, con cinco torres cilíndricas (sobresaliendo la central, de mayores dimensiones) coronadas por merlones de remate esférico y dispuestas sobre una base circular elevada, la cual presenta concavidades cilíndricas.

\section{ALBAHAQUEROS}

Recipientes cuya función responde a la de un tiesto, conteniendo plantas de tamaño pequeño o medio, y a los que se les atribuye cierto carácter ornamental (González Martí 1944: 236). Presentan cuerpo troncocónico invertido de paredes rectas o levemente curvas que contaría con una base plana. El interior, sin cubierta, supone otro rasgo definitorio para su identificación.

Técnica de elaboración: a torno, excepto los añadidos decorativos, modelados a mano.

Tratamiento de la superficie: vedrío estannífero en el exterior. 
GRUPO IV: CERẢMICA DE USO DOMÉSTICO DIVERSO

FORMA 20. Lebrillos

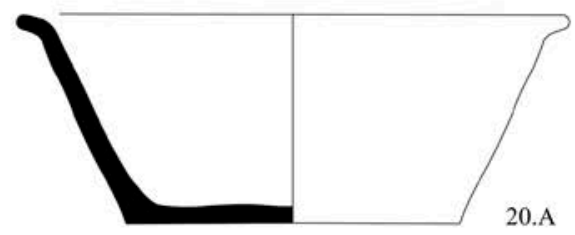

FORMA 21. Braseros

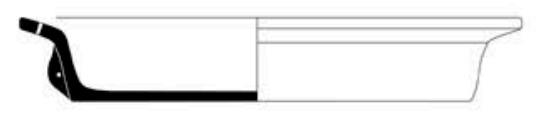

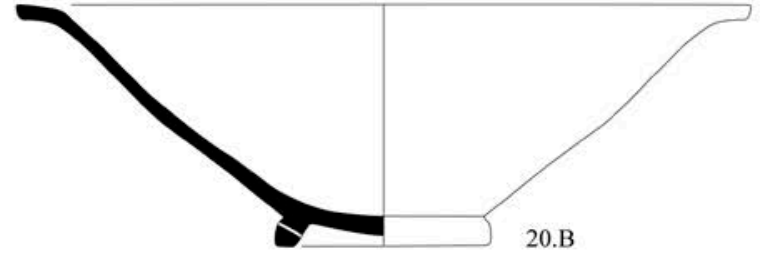

FORMA 22. Vertedores-refrescadores

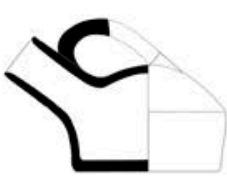

FORMA 23. Candiles

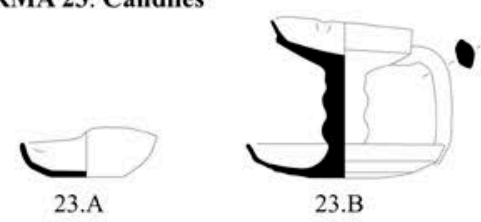

FORMA 24. Útiles de escritorio
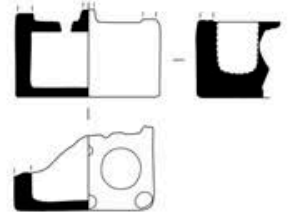

24.A

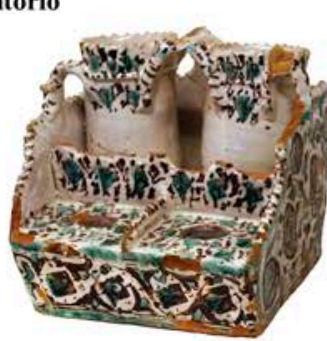

24.B.1

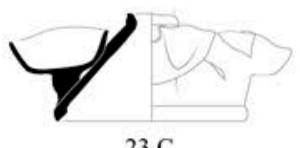

23.C

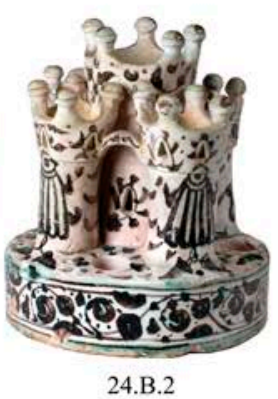

It yos

FORMA 25. Albahaqueros

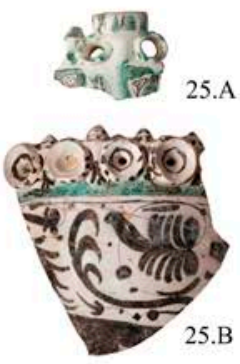

FORMA 26. Aguamaniles

FORMA 27. Juguetes
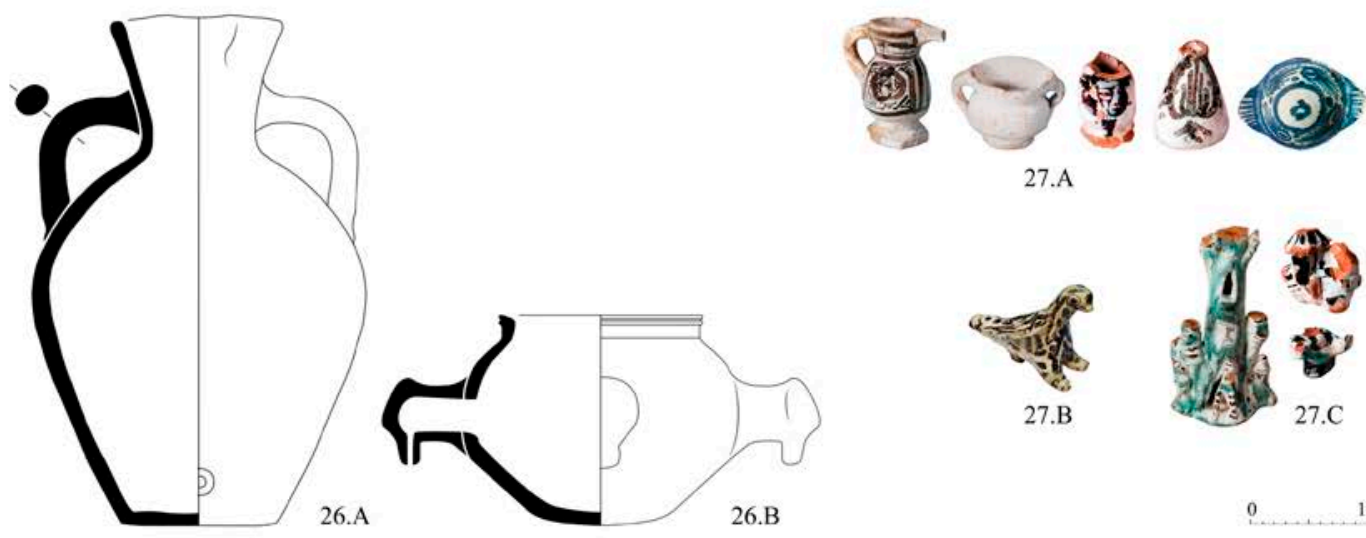

27.A
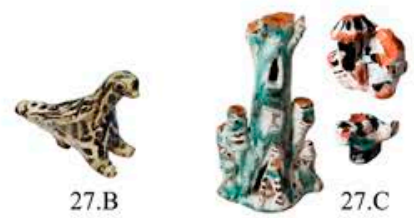

0

Fig. 7: GRUPO IV: Cerámica de uso doméstico diverso. 
Decoración: pintada en verde y negro.

Posibles precedentes: alfabeguers de Paterna y Manises (González Martí 1944: 236-237, fig. 300; Pascual y Martí 1986: fig. 31).

Paralelos en la Corona de Aragón: además de cómo modelo, recipientes como los referidos en el punto anterior también suponen los paralelos de este tipo, produciéndose de manera coetánea.

Tipos y subtipos:

25.A. Borde rematado por una crestería de círculos calados y pequeñas almenas.

25.B. Borde de botones aplicados y pequeñas almenas.

\section{AGUAMANILES}

Recipientes cerrados destinados a contener y servir agua para, presumiblemente, el lavado de manos en el momento previo a la comida (Timón et al. 1977: 7). Cuentan con un orificio vertedor o caño en sus cuerpos por donde saldría el líquido, que sería recogido en alguna bandeja o vasija semejante de cerámica u otro material.

Técnica de elaboración: a torno, vertedores modelados a mano.

Tratamiento de la superficie: vedrío estannífero.

Decoración: pintada en verde y negro.

Posibles precedentes: aguamaniles nazaríes con vertedores zoomorfos podrían ser los antecedentes del tipo B (Martínez Caviró 1991: figs. 42 y 60).

Paralelos en la Corona de Aragón: en Barcelona se documentan piezas semejantes al tipo A (Beltrán 2006: 47, 51).

Tipos y subtipos:

26.A. Cuerpo ovoide, cuello exvasado y base plana. Dos asas de sección redonda que apoyan en el hombro y pico vertedor en eje de $90^{\circ}$ con éstas, por el que se diferencia de la forma cántaros, además de la cubierta esmaltada y el orificio de salida en la parte inferior del cuerpo.

26.B. Cuerpo globular achatado en cuya mitad presenta cuatro caños vertedores en forma de cabezas de animal, de los cuales sólo uno es funcional. Boca ancha de labio biselado.

\section{JUGUETES}

Objetos de pequeño tamaño en general y destinados esencialmente al ocio. En algunos casos podrían contar asimismo con función didáctica, como las miniaturas de vajilla, probablemente orientadas a que las niñas se familiarizasen con objetos de uso cotidiano, como se interpreta en el caso andalusí (Marinetto 1997: 185-186).
Técnica de elaboración: modelado a mano.

Tratamiento de la superficie: vedrío estannífero.

Decoración: pintada en verde, negro, verde y negro o azul.

Posibles precedentes: juguetes andalusíes, califales y nazaríes, como piezas de vajilla en miniatura (Marinetto 1997: 186); sifâra, silbatos con formas de animales (Rosselló 2002: 100-101); o piezas de juegos como el jinete hallado en Zaragoza, posible pieza de ajedrez (Gutiérrez y De Miguel 2010: 444, fig. 18).

Paralelos en la Corona de Aragón: pequeñas piezas de la zona valenciana con morfologías del servicio de mesa, definidas como juguetes por su reducido tamaño (González Martí 1944: 257-258).

Tipos y subtipos:

27.A. Imitación en miniatura de formas de la vajilla, incluyendo algunas decoraciones.

27.B. Figuritas zoomorfas (habitualmente aves) dotadas de un orificio biselado de insuflación y otro para la salida del aire, pudiendo identificarse con un silbato.

27.C. Representaciones de figuras humanas, animales y arquitectónicas.

\section{CONCLUSIONES Y PERSPECTIVAS DE INVES- TIGACIÓN}

Mediante esta propuesta inicial de sistematización ha tratado de ofrecerse una visión general de la cerámica de uso doméstico producida en Teruel desde el último tercio del s. XIII hasta el final de la Edad Media. Además de la distinción de veintisiete formas, cincuenta y tres tipos y treinta y dos subtipos, deben destacarse los siguientes puntos:

En primer lugar, se reafirma la deuda de la producción turolense medieval con respecto a la andalusí, ya enunciada por M. Almagro y L. M. Llubiá (1962) y ratificada por J. Ortega (2002) y M. I. Álvaro (2002). Si bien ésta es la principal influencia, la revisión de sistematizaciones y tipologías permite establecer una dependencia de la cerámica cristiana de los ss. IX al XII, en especial de recipientes de cocina procedentes de la zona catalana, cuya influencia llegaría con los nuevos pobladores y sus costumbres y hábitos alimenticios.

En segundo, la individualización de tipos y subtipos evidencia una paulatina transformación de algunas formas. Entre los rasgos más apreciables se encuentra la tendencia, hacia las décadas finales del s. XIV y principios del XV, al abandono de cuerpos globulares y piriformes, 
predominando a partir de entonces los campaniformes o tubulares, así como la desaparición del pie anular, sustituido por bases planas.

En tercero, a nivel material y tecnológico, el análisis macroscópico de las pastas ha permitido la distinción, grosso modo, de cuatro diferentes. Además de su dependencia con respecto a la función del recipiente, siendo la B exclusiva de la vajilla de fuego, destacar, parejo al cambio en formas y decoraciones, la evolución hacia una mayor complejidad del tratamiento de la arcilla, pasando de pastas rojizas poco depuradas de finales del s. XIII y que predominan durante el XIV, a otras obtenidas con un procedimiento más elaborado, propias del s. XV.

En cuarto y último, mencionar las numerosas piezas valencianas recuperadas junto con las locales, evidencia de las relaciones e intercambios comerciales entre ambas regiones. La frecuente llegada de recipientes cerámicos desde zonas del Mediterráneo peninsular, en especial del entonces Reino de Valencia, supuso que algunos de los tipos y subtipos distinguidos guarden una gran similitud, tanto en forma como en decoración, con piezas producidas en los alfares de Paterna y Manises.

Puesto que el presente artículo supone una primera propuesta, a modo de punto de partida, de lo que será una investigación más extensa y exhaustiva, la sistematización referida queda abierta a ser ampliada y matizada en próximos trabajos; partiendo de la revisión de un mayor número de piezas y la consideración de los hallazgos más recientes en el área urbana de Teruel, entre otras cuestiones. Todo ello, con el objetivo de lograr un mejor conocimiento no sólo de esta producción cerámica sino también de la sociedad que la creó, desarrolló y le dio uso.

\section{BIBLIOGRAFÍA}

ALMAGRO BASCH, M.; LLUBIÁ MUNNÉ, L. M. (1962): La Cerámica de Teruel, Teruel.

ÁLVARO, M. I. (1981): Léxico de la cerámica y alfarería aragonesas, Zaragoza.

ÁLVARO, M. I. (1987): La cerámica de Teruel, Zaragoza.

ÁlVARO, M. I. (2002): Cerámica Aragonesa II, Zaragoza.

ÁLVARO, M. I. (2003): Las artes decorativas mudéjares, Els vestits del Saber: Enquadernacions mudèjars a la Universitat de València (N. Piqueras, coord.), Valencia, 175-184.

ÁLVARO, M. I. (2005): La emblemática en la cerámica, Emblemata $11,349-406$.

AMIGUES, F. (1986): Un albahaquero común de cerámica común en el Museo de Paterna, Archivo de Arte Valenciano 67, 97-102.
AMIGUES, F. (1987): La céramique domestique des ateliers mudéjares de Paterna (Valencia), Mélanges de la Casa de Velázquez 23, 151-173.

AMIGUES, F. (1995): La cerámica gótico-mudéjar valenciana y las fuentes de inspiración de sus temas decorativos, Spanish medieval ceramics in Spain and the British Isles (C. Gerrard, A. Gutiérrez, A. Vince, eds.), Oxford, 141-158.

AMIGUES, F.; MESQUIDA, M. (1987): Un horno medieval de cerámica. "El testar del Molî" Paterna (Valencia), Madrid.

ATRIÁN JORDÁN, P. (1979): Informe sobre las excavaciones realizadas en la Plaza de la Judería, Boletín informativo de la Diputación Provincial de Teruel 53, 44-46.

BAZZANA, A. (1979): Céramiques médiévales: Les méthodes de la description analytique appliquées aux productions de l’Espagne Orientale, Mélanges de la Casa de Velázquez 15, 135-185.

BAZZANA, A. (1990a): La cerámica hispano-musulmana: problemas técnicos, La cerámica islámica en la ciudad de Valencia (II), Valencia, 41-60.

BAZZANA, A. (1990b): Ensayo de tipología de la cerámica musulmana del antiguo Sharq al-Ándalus, La cerámica islámica en la ciudad de Valencia (II), Valencia, 143-162.

BELTRÁN DE HEREDIA, J. (2006): La ceràmica de les voltes del convent de Sant Agustí de Barcelona. Noves formes per la tipologia de la ceràmica comuna baix medieval de Barcelona, Arqueologia Medieval 2, 46-67.

BOLÒS, J.; LLOPART, J.; SERRA, A.; SUNYOL, M.; VENDRELL, M. A. (1986): Ceràmiques medievals del Museu d'Arts, Indústries i Tradicions Populars de Barcelona, Actas del primer Congreso de Arqueología Medieval Española, vol. 5, Diputación General de Aragón, Zaragoza, 683-702.

CASABONA, J. F.; IBÁÑEZ GONZÁLEZ, E. J.; DELGADO, J. (1997): Excavaciones arqueológicas en la calle Ripalda/ Temprado de Teruel, Arqueología Aragonesa 1993, Zaragoza, 253-257.

CEBOLLA, J. L.; MELGUIZO, S.; RUIZ, F. J. (2009): La Judería nueva en Calatayud. Visión arqueológica, Congreso de Arqueología judía medieval en la Península Ibérica. Balance y perspectivas. Murcia, 26-28 de febrero de 2009 (J. García, coord.), 1-13.

COLL, J. (2009): La cerámica valenciana: (apuntes para una síntesis), Valencia.

COLL, J.; MARTÍ, J.; PASCUAL, J. (1988): Cerámica y cambio cultural: el tránsito de la Valencia islámica a la cristiana, Valencia.

DE SUS, M. L. (2003): Excavación arqueológica en el Coso-Plaza España en el marco del proyecto "Nuevo Tubo-Puerta Cinegia" de Zaragoza, Saldvie 3, 363-372.

ESCO, C.; SÉNAC, M. P. (1987): Un Hisn de la marche supérieure d'Al-Andalus: Piracés (Huesca), Mélanges de la Casa de Velázquez 23, 125-150.

DOI: https://doi.org/10.3406/casa.1987.2487 
GÓMEZ BELLARD, C.; PÉREZ BALLESTER, J. (2004): Imitaciones de vasos plásticos en el mundo ibérico, La vajilla ibérica en época helenística (siglos IV-III al cambio de era) (R. Olmos, P. Rouillard, coords.), Madrid, 31-48.

GONZÁLEZ MARTÍ, M. (1944): Cerámica del Levante español. Siglos medievales. Tomo I: Loza, Barcelona.

GUTIÉRREZ GONZÁLEZ, F. J. (2007): La excavación arqueológica del Gran Teatro Fleta de Zaragoza. Catas en 2001 y campañas 2002 y 2005, Salduie 7, 281-306.

GUTIÉRREZ GONZÁLEZ, F. J.; DE MIGUEL MILLÁN, C. (2010): La cerámica del arrabal meridional de Zaragoza durante la Edad Media, Actas de las I Jornadas de Arqueología medieval en Aragón, Balances y novedades (J. M. Ortega, C. Escriche, eds.), Teruel, 427-459.

HERNÁNDEZ PARDOS, A.; MONTEAGUDO, R.; FRANCO CALVO, J. G. (2004): La plaza de la Judería de Teruel. La intervención arqueológica en 2004, Memorias de Arqueología Aragonesa, 2004, en línea, (sin paginar), <https:// www.academia.edu/10490931/_2004_La_plaza_de_la_ Judería_de_Teruel._La_intervención_arqueológica_ en_2004> (Consulta 28-VIII-2017).

HERNÁNDEZ PARDOS, A. (2014): La cerámica feudal entre mediados de los siglos XIII y XIV, según el repertorio de la plaza de la Judería de Teruel, Arqueología y Territorio Medieval 21, 177-206.

HERRERO, M. Á.; IBÁÑEZ, J. (2007): Excavaciones arqueológicas en el solar de la c/ Temprado $\mathrm{n}^{\circ}$ 5-7 y c/Amantes n ${ }^{\circ} 18$, Arqueología aragonesa 1995-2005 (B. Gimeno, coord.), (sin paginar).

IBÁÑEZ GONZÁLEZ, I. (2010): La arqueología urbana del Teruel medieval y moderno: resultados y visión crítica, I Jornadas de Arqueología medieval en Aragón. Balances y novedades (J. M. Ortega, C. Escriche, eds.), Zaragoza, 289-332.

JUSTE, M. N.; MOTIS, M. A. (2014): La judería de Barbastro y el hallazgo de unos fragmentos de Hanukkiyah, Somontano 9, 7-42.

LERMA, J. V.; MIRALLES, I.; SOLER, M.P. (1986): Cerámicas musulmanas de "El Tossalet de Sant Esteve", Valencia, Segundo Coloquio Internacional de Cerámica Medieval en el Mediterráneo Occidental (J. Zozaya, coord.), Madrid, 155-163.

MARINETTO, P. (1997): Juguetes y silbatos infantiles de época nazarí, Miscelánea de Estudios Árabes y Hebraicos 46, 183-205.

MARTÍ, J.; PASCUAL, J. (1995): Tradición e innovación en el repertorio formal de la cerámica valenciana bajomedieval, Spanish Medieval Ceramics in Spain and the British Isles (C. Gerrard, A. Gutiérrez, A. Vince, eds.), Oxford, 159-176.

MARTÍ, J.; PASCUAL, J.; ROCA, L. (2007): Entre el «know how» y el mercado. El horizonte cerámico de la colonización feudal en el territorio valenciano, La cerámica en entornos urbanos y rurales en el Mediterráneo medieval, Ceuta, 79-158.
MARTÍNEZ CAVIRÓ, B. (1991): Cerámica hispanomusulmana. Andalusí y mudéjar, Madrid.

MENÉNDEZ FUEYO, J. L. (2005): Apuntes para el estudio de contenedores cerámicos medievales: las tinajas de las bóvedas de la iglesia de Santa María de Alicante, Santa María descubierta. Arquitectura, Arqueología y Cerámica, Alicante, 72-119.

MESQUIDA, M. (1990a): La cerámica de Paterna en el siglo XIII, Paterna.

MESQUIDA, M. (1990b): Candelers i cresols medievals, Paterna. MESQUIDA, M. (2001): Las ollerías de Paterna, Paterna.

OLIVAR, M. (1952): La cerámica trecentista en los países de la Corona de Aragón, Barcelona.

ORTEGA, J. M. (2002): ...operis terre turolii: la cerámica bajomedieval en Teruel, Teruel.

ORTEGA, J. M. (2012): Bebidas manipuladas: vino, cerámica y convivialidad en Teruel durante la Baja Edad Media, Actas del XV Congreso Anual de la Asociación de Ceramología. La cerámica en el mundo del vino y del aceite, Navarra, 44-67.

ORTON, C.; TYERS, P.; VINCE, A. (1997): La cerámica en Arqueología, Barcelona.

PADILlA, C.; MAICAS, R.; CABRERA, P. (2002): Diccionario de Materiales Cerámicos, Madrid.

PADILLA LAPUENTE, J. I. (1984): Contribución al estudio de las cerámicas grises catalanas de época medieval: El taller, hornos y producción de Casampons (Berga), Acta historica et archaeologica mediaevalia, Anexo 2: Ceràmica grisa $i$ terrissa popular de la Catalunya medieval (M. Riu, coord.), 99-143.

PASCUAL, J.; MARTÍ J. (1986): La cerámica verde-manganeso bajomedieval valenciana, Valencia.

PASTOR, A. (1992): La cocción de los materiales cerámicos, Tecnología de la cocción cerámica desde la Antigüedad a nuestros días: ponencias del Seminario celebrado en el Museo de Alfarería en Agost (Alicante) del 5 al 6 de octubre de 1990, Asociación de Ceramología, Agost, 19-38.

PÉREZ-ARANTEGUI, J. (2010): La cerámica medieval y moderna de Teruel: aspectos tecnológicos, I Jornadas de arqueología medieval en Aragón: balances y novedades. Actas: Teruel, 15-17 de junio de 2006, (J. Ortega, C. Escriche, eds.), Teruel, 403-414.

PÉREZ-PIÁ, D. (2018): Propuesta de seriación de la cerámica vidriada bajomedieval de Teruel, Actas de las IX Jornadas de Jóvenes en Investigación Arqueológica. Santander, 8-11 junio 2016 (L. Agudo et al. eds.), Santander, 513-519.

POMARES VERGARA, J. (1985): Breve estudio sobre un probable candil judío, ARSE. BCAS 20, 1985, 487-493.

RODRÍGUEZ DEL MAZO, R.; GIBELLO, V. (2010): Excavación arqueológica en el solar situado entre las calles Bajo Los Arcos y Mosen Peras, Teruel. Agosto-septiembre de 2005, I Jornadas de Arqueología medieval en Aragón. Balances y novedades (J. M. Ortega, C. Escriche, eds.), Zaragoza, 461-480. 
ROSSELLÓ BORDOY, G. (1978): Ensayo de sistematización de la cerámica árabe en Mallorca, Palma de Mallorca.

ROSSELLÓ BORDOY, G. (1983): Nuevas formas en la cerámica de época islámica, Bolletí de la Societat Arqueològica Lul-liana 39, 337-360.

ROSSELLÓ BORDOY, G. (2002): El ajuar de las casas andalusíes, Málaga.

RÍU RÍU, M.; RÍU DE MARTÍN, M. C. (1995): Las cerámicas medievales catalanas, Spanish medieval ceramics in Spain and the British Isles (C. Gerrard, A. Gutiérrez, A. Vince, eds.), Oxford, 113-128.

SÁNCHEZ-LAFUENTE PÉREZ J. (1981): A propósito de un candil musulmán hallado en Albarracín, Teruel 66, 171-174.
TIMÓN TIEMBLO, M. P.; SÁNCHEZ, E.; SALMADOR, N. (1977): La cerámica en el ciclo de la vida humana, Narria: Estudios de artes y costumbres populares 8, 5-8.

VILLANUEVA ZUBIZARRETA, O. (1994): Tres moldes cerámicos recuperados en el alfar medieval de la calle Duque de la Victoria $n^{\circ}$ 23, BSEAA 60, 267-276.

VILLANUEVA MORTE, C. (2007): Estudio de la producción y comercialización de la cerámica bajomedieval entre los reinos de Aragón y Valencia, Anales de la Universidad de Alicante. Historia Medieval XIV, 249-287.

WITTLIN, C. J. (1976) Un inventario turolense de 1484: Los Sánchez Muñoz, herederos del papa Clemente VIII, Archivo de Filología Aragonesa 18-19, 187-215.

ZOZAYA, J.; LLAGOSTERAS, E. (1977): Análisis radiológico de un tintero califal en el M.A.N., RABM LXXX, 911-917. 